\title{
Fluid sampling from oceanic borehole observatories: design and methods for CORK activities (1990-2010) ${ }^{1}$
}

\author{
C.G. Wheat, ${ }^{2}$ H.W. Jannasch, ${ }^{3}$ M. Kastner, ${ }^{4}$ S. Hulme, ${ }^{2}$ J. Cowen, ${ }^{2}$ K.J. Edwards, ${ }^{5}$ \\ B.N. Orcutt, ${ }^{2}$ and B. Glazer ${ }^{6}$
}

\section{Chapter contents}

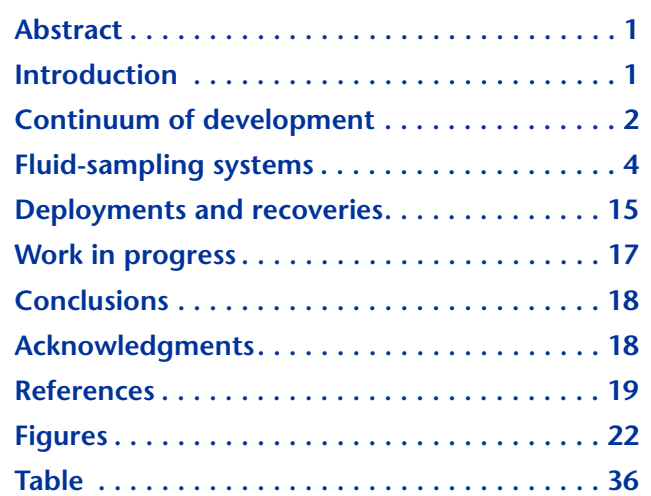

'Wheat, C.G., Jannasch, H.W., Kastner, M., Hulme, S., Cowen, J., Edwards, K.J., Orcutt, B.N., and Glazer, B., 2011. Fluid sampling from oceanic borehole observatories: design and methods for CORK activities (1990-2010). In Fisher, A.T., Tsuji, T., Petronotis, K., and the Expedition 327 Scientists, Proc. IODP, 327: Tokyo (Integrated Ocean Drilling Program Management International, Inc.).

doi:10.2204/iodp.proc.327.109.2011

'Expedition 327 Scientists' addresses.

${ }^{3}$ Monterey Bay Aquarium Research Institute, Moss Landing CA 95039, USA.

${ }^{4}$ Scripps Institution of Oceanography, University of California, San Diego, La Jolla CA 92093, USA.

${ }^{5}$ Department of Biological Sciences, Marine Environmental Biology Section, University of Southern California, Los Angeles CA 90089, USA. ${ }^{6}$ Department of Oceanography, School of Ocean and Earth Sciences and Technology, University of Hawaii, Honolulu HI 96822, USA.

\section{Abstract}

Subseafloor borehole observatories ("CORKs") are currently the best mechanism by which fluids from subsurface hydrologic zones can be collected to evaluate the composition, evolution, and consequence of fluid circulation in oceanic crust. The fluidsampling capabilities of CORKs have evolved over two decades, spanning the Ocean Drilling Program and Integrated Ocean Drilling Program. The fluid-sampling system for the original CORK design consisted of a single polytetrafluoroethylene (PTFE) tube that connected to a valve at the seafloor and ended at depth in the formation. Through successes and disappointments coupled with community desires and efforts, significant iterations of CORK design and capabilities have led to the development of a range of crustal fluid-sampling systems. These iterations continue today with the development of new borehole capabilities, sensors, and samplers. This paper discusses these developments and transitions, highlighting the pros and cons of various designs, materials, and decisions. Although the evolution of CORK design has taken years because of the infrequency of CORK deployments and sample recovery operations, we as a community are now in a position to report on groundbreaking results that will enhance our understanding of subseafloor hydrogeology, crustal evolution, geochemical fluxes, microbial ecology, and biogeochemical processes, as indicated by the wealth of work referenced herein and by the complexity and flexibility of present and future designs.

\section{Introduction}

In the past several decades the scientific community has recognized the importance of fluid flow through the oceanic crust and the impact of this flow, coupled with biotic and abiotic reactions, on the physical, chemical, and biological evolution of the crust and the overlying oceans. These revelations stem indirectly from global data sets of heat flow, sediment thickness, basaltic alteration, pore water composition, and seawater-basalt laboratory studies (e.g., Alt, 2004; Edwards et al., 2005; Parsons and Sclater, 1977; Seyfried and Bischoff, 1979; Wheat et al., 2003b; Wheat and Mottl, 2004). However, each of these data sets is limited, and the goal of collecting pristine formation fluids from the basaltic crust and zones of hydrologic interest has been difficult to reach. Until recently, the only means of collecting such fluids was in 
open boreholes after drilling operations ceased; however, this tactic presented its own difficulties (e.g., Mottl and Gieskes, 1990; Gieskes and Magenheim, 1992; Magenheim et al., 1992, 1995).

The desire to elucidate crustal processes, define oceanic geochemical budgets, and investigate the subsurface biosphere harbored in oceanic crust has led to the development of fluid-sampling and experimental capabilities in subseafloor borehole observatories ("CORKs") as an alternative to previous attempts (Davis et al., 1992). The basic concept behind a CORK is to drill into the hydrologic zone of interest, case the overlying material, seal the borehole from exchange with seawater, instrument the hydrologic zone, and monitor physical, chemical, and biological changes while the borehole recovers from disturbances induced during the drilling process and for natural variability thereafter.

The initial CORKs were deployed in 1990 during Ocean Drilling Program (ODP) Leg 139 at Sites 857 and 858 in Middle Valley on the Juan de Fuca Ridge (Davis, Mottl, Fisher, et al., 1992), which is a site of active high-temperature $\left(264^{\circ} \mathrm{C}\right)$ hydrothermal venting (Butterfield et al., 1994; Cruse and Seewald, 2006). Since this initial deployment, CORKs have been deployed in a sedimented mid-ocean ridge and in the flanks of mid-ocean ridges and convergent margins during seven ODP legs and six Integrated Ocean Drilling Program (IODP) expeditions (Table T1; Fig. F1). Numerous scientific papers have been published based on data from these CORKs. Two papers in particular are of interest to the general scientific community. One is a compilation of firstorder scientific results spanning hydrogeological, physical, and geochemical conclusions (Kastner et al., 2006). The other highlights the evolution of CORK design and physical sensors, presents methods of submersible operation, and provides an outlook for future work and funding pathways (Becker and Davis, 2005). This paper is also designed for a general audience but focuses on fluid-sampling capabilities and chemical sensors associated with CORK observatories during the past two decades.

The goal of this paper is to provide a framework for future scientists to design fluid-sampling and sensor schemes that best suit their immediate scientific concerns but that are flexible enough to accommodate unforeseen experiments and new fields of study. First, we present CORK engineering efforts as a continuum of development, generally following advances incorporated with the evolution of CORK sampling systems. We then focus on detailed fluidsampling efforts, dividing those associated with seafloor-deployed systems from those deployed within the borehole (downhole systems). We present bore- hole efforts first because they are primarily focused on the central technology of continuous fluid samplers (OsmoSamplers) (Jannasch et al., 2004). In contrast, OsmoSamplers are just one of several different types of samplers and sensors deployed at the seafloor. Lastly, we present engineering works in progress that will advance sampling and analytical capabilities.

\section{Continuum of development Initial CORK design}

In simple terms, the initial CORK design consisted of a steel casing that was open to the formation at depth and was sealed at the seafloor (Fig. F2) (Davis et al., 1992). The sealing mechanism consisted of a removable plug with a pressure sensor and data logger. A cable with 10 thermistors was suspended below the plug, and fluid sampling was accessible through a ball valve attached to polytetrafluoroethylene (PTFE) tubing, which was attached to the thermistor cable inside the borehole. The first CORK deployments occurred at Sites 857 and 858 in an active hydrothermal system. Pressures at depth were expected to be greater than hydrostatic. Thus, it was expected that once the ball valve was opened, fluids from depth would ascend the PTFE tubing to be sampled at the seafloor. However, the PTFE tubing was not stiff enough and kinked upon deployment.

The subsequent CORK deployment on Hydrate Ridge, Cascadia margin (Holes 889C and 892B), used the same basic design without PTFE tubing (Westbrook, Carson, Musgrave, et al., 1994). However, this design required fluids to ascend through the mild steel casing before being sampled, leading to contamination, especially for transition metals (e.g., Wheat et al., 2004). For 403 days an instrument package was connected to the sampling port to monitor flow driven by natural overpressure. This package included two continuous fluid samplers (OsmoSamplers; more details are given below), pressure sensors, flow meters, and chambers for gas hydrate and carbonate precipitation from which microbial communities could be extracted. The formation of gas hydrate began 45 days into the experiment and reduced the flow rate considerably.

This initial CORK design was also used on the next four deployments (ODP Legs 156, 168, 174B, and 195) (Shipley, Ogawa, Blum, et al., 1995; Davis, Fisher, Firth, et al., 1997; Becker, Malone, et al., 1998; Salisbury, Shinohara, Richter, et al., 2002). To minimize contamination with the casing, OsmoSamplers were attached to the thermistor cable during each expedition, with the exception of Leg 174B 
(Fig. F2). These samplers were placed in open holes whenever possible, below the mild steel casing.

\section{Advancement in CORK design: ACORK and CORK-II}

A major change in CORK design, known as the advanced CORK (ACORK), was used during ODP Leg 196 (Mikada, Becker, Moore, Klaus, et al., 2002). Instead of having all of the sensors in the borehole, pressure sensors for the ACORK were attached to multiple stainless steel tubes that were bundled in a protective hard-plastic coating (called an umbilical) and attached to the outside of the casing. An umbilical is designed to terminate at a depth horizon of interest. This horizon is isolated by the use of packers, which are like giant tires that are inflated to fill the annulus of the borehole. Individual tubes within the umbilical terminate at miniscreens, which are 1-2 m long and $\sim 3 \mathrm{~cm}$ in diameter, with a wire wrap that provides an effective open cross section of $\sim 15 \%$. The umbilical and miniscreens are attached to the outside of the CORK casing using plastic zip ties, stainless steel hose clamps, and duct tape.

The Leg 196 ACORK design was further expanded on with the CORK-II design, which included an umbilical attached to the outside of the casing and an open borehole where instrument strings can be placed in a hydrologic horizon (Fig. F3) (Morris, Villinger, Klaus, et al., 2003; see figs. F3, F4 in Fisher et al., 2005). From deepest to shallowest, borehole instrument strings consist of a sinker bar, OsmoSampler packages, Spectra cable, self-recording temperature loggers, and sealing plugs. The plugs were modified to seal with a tapered O-ring seat and gravity instead of by latching in place within the CORK, which made the plugs difficult to remove. Gravity plug seals were used to avoid issues with the pulling tool, which is heavy and difficult to manipulate. These plugs also require a separate submersible dive to release the latch and often were not effective, requiring additional dives. Another change was to place gravity seals near the bottom of the casing with a redundant seal at the seafloor. The lower seal, located just above the OsmoSampler package, limited exposure of borehole fluids to mild steel casing.

Two novel downhole packages were deployed in CORK-IIs during ODP Leg 205 on the Costa Rica margin (Morris, Villinger, Klaus, et al., 2003; Jannasch et al., 2003; Solomon et al., 2009). The OsmoSampler packages deployed in Hole 1255A were housed within a steel casing with a titanium stinger. This stinger protects sample intakes and penetrates a seal that opens to a portion of perforated and wrapped casing (a "screened" section), allowing fluid exchange among the formation, borehole, and sample intakes. When the stinger is removed, the valve is pulled closed, maintaining the pressure of the formation at in situ conditions. This string was recovered in 2004 and redeployed with the R/V JOIDES Resolution, but it was not properly seated when redeployed. During recovery attempts in 2009 the line parted at the steel package.

In contrast, the OsmoSampler packages in Hole $1253 \mathrm{~A}$ were housed in steel casing and exposed to the formation through the open portion of the borehole and within the protective casing, similar in style to those deployed during Leg 168 that used a polycarbonate housing. When the downhole packages were recovered by the JOIDES Resolution in 2004, one of the two identical packages was lost during handling procedures in the moonpool. Two packages were deployed in 2004; however, only one package - the package protected by the casing-was recovered using the DSRV Alvin (Woods Hole Oceanographic Institution) in 2009. A new string with a polycarbonate instead of steel housing was deployed in 2009.

CORK-II systems were deployed in two new holes during IODP Expedition 301 (Holes U1301A and U1301B), and the original-style CORK deployed in ODP Hole 1026B was recovered, providing substrate for microbial studies (Nakagawa et al., 2006; Steinsbu et al., 2010), and was replaced with a CORK-II (Fisher et al., 2005). OsmoSampler packages were deployed within the boreholes with a gravity seal at depth and at the seafloor. Additional fluid samplers were deployed on the wellhead, which was partitioned into pressure, chemical, and microbiology bays, each with its own system of valves (Fig. F4). These CORK-IIs also included a dedicated umbilical for microbiological sampling and downhole experimentation (Fisher et al., 2005; Orcutt et al., 2011).

\section{Current CORK advancements: L-CORK and genius plug}

The lateral CORK (L-CORK) was modified from the CORK-II design to add a $10.2 \mathrm{~cm}$ (4 inch) diameter ball valve connected to a break-out tube in the CORK body at the wellhead to hold a novel inductive flow meter, which provides an additional way to access downhole samplers, sensors, and fluids. L-CORKs were deployed during IODP Expedition 327 on the Juan de Fuca Ridge flank (Fisher, Wheat, et al.) and will be deployed during IODP Expedition 336 (Edwards et al., 2010) (Fig. F3). A second major change in the L-CORK design was the addition of a top valve that is latched in place. This design was instituted to avoid deployment issues with the top plugs that were encountered during Expedition 301. 
A third modification included redundant borehole seals. A combination of inflatable and waterswellable packers was employed. This was the first scientific use of swellable packers, which are $1.5 \mathrm{~m}$ in length and made of FREECAP FSC11 polymer (TAM International). A fourth modification was a deployment scheme that placed all of the borehole OsmoSampler packages within perforated epoxycoated drill collars. This modification was implemented because $\sim 50 \%$ of all downhole packages that extend beyond the protection of the cased hole are now entombed in the crust. Drill collars serve three purposes: (1) they maintain tension on the $11.4 \mathrm{~cm}$ (4.5 inch) diameter CORK casing; (2) perforations allow fluid circulation within a protected environment; and (3) the baked coating on the inside and outside of the collars minimizes contamination for microbiological and geochemical studies (Orcutt et al., 2010). Structurally, these drill collars were deemed critical because casing is strong in tension and relatively weak in compression. This probably contributed to the failed CORK deployments during Legs 195 and 206 and Expedition 301. A final modification was a new valve and coupler system to access fluids from the umbilical (Fig. F5). This change from the Aeroquip standard was necessary because the Aeroquip connection is mechanically difficult to complete for submersible pilots, it is difficult to discern whether the connection has been made, and constant maintenance is needed (Fisher, Wheat, et al.).

The L-CORK design will be employed during Expedition 336, but with the use of fiberglass casing (Edwards et al., 2010). Fiberglass was chosen to minimize the amount of potential contamination from mild steel casing. Fiberglass is strong in tension (as is steel) but weaker than steel in compression, yet it is more flexible than steel.

No fluid-sampling capabilities were incorporated into CORKS deployed during IODP Expeditions 319 (Saffer, McNeill, Byrne, Araki, Toczko, Eguchi, Takahashi, and the Expedition 319 Scientists, et al., 2010) and 328 (Davis et al., 2010). However, during IODP Expedition 332 an OsmoSampler and a microbial colonization experiment (Orcutt et al., 2010; described in more detail below) were deployed in Hole C0010A as part of the "genius plug" to detect changes in borehole fluid and microbial conditions in the screened zone that bisects a major fault in the Nankai accretionary system (Fig. F6) (Kopf et al., 2010). The sampler and microbial experiments were designed to be as compact as possible and fit within a small extension below the pressure port. This small size limits the amount of sample that can be collected.

\section{Fluid-sampling systems}

During the two decades of CORK evolution described above, the corresponding fluid-sampling systems, sensors, and experiments also have evolved to improve our ability to collect pristine fluids from CORKs. The success of these systems requires that the hole recover from drilling disturbances, which include (1) surface seawater used as a drilling fluid to wash cuttings from the hole, (2) bottom seawater that enters naturally because a newly drilled hole is underpressured relative to neighboring crust, (3) drilling mud (clays to barite) used to keep the hole open, (4) cement used to seal casing, (5) grease used to lubricate steel threads, and (6) steel casing. The time required for borehole conditions to recover from drilling and installation disturbances varies but often requires many months to years. Given these variable conditions and the desire to detect borehole recovery events, CORK fluid samplers are designed to operate continuously under a range of conditions.

Fluid-sampling systems are categorized as either downhole or seafloor instruments. Seafloor instruments rely on a connection to the formation via umbilicals that span the length of the CORK and terminate at sampling bays on the wellhead. Seafloor fluid-collection systems have no size restriction and the advantage of being able to be recovered and modified on a yearly basis. The downside of seafloor sampling is that samples must ascend a tube before collection, and in situ temperature and pressure are not maintained. In contrast, downhole packages are size restricted and must remain in the borehole for years because opening the borehole disturbs the formation, especially if the formation is underpressured relative to hydrostatic. However, downhole packages are positioned in well-ventilated boreholes at in situ temperature and pressure. Fluids in this environment are at least as pristine as those that must ascend hundreds of meters of small-bore stainless steel or PTFE tubing to surface collection systems. However, recent results indicate that the stainless steel tubing does not contribute to the contamination of trace metals in solution provided the formation fluid is continuously ascending (Hulme and Wheat, 2010). Nevertheless, given the many obstacles related to CORK operations, redundant systems are critical in CORK design and sample-collection strategies. Below we describe in detail both types of fluidsampling systems, starting with downhole systems.

\section{Guiding principles for downhole systems}

The principal goals of downhole fluid-sampling systems are to collect pristine fluids under in situ pressure, temperature, and chemical conditions and to 
conduct experiments using these fluids within a natural setting. Initially, there was a strong desire to distance the samplers from the steel casing, placing samplers in open boreholes whenever possible. This practice was used for several deployments until it was realized that many holes are unstable no mater how much hole is open below the samplers and how round ("to gauge") the hole is, as determined with the downhole caliper tool. Hole instability is believed to be the reason why initial downhole packages from Holes 1025C, 1026B, and U1301B and the second deployment in Hole 1253A were not recoverable. Thus, beginning with Expedition 327 all of the downhole packages were safely deployed in perforated coated steel or fiberglass casing.

Placing samplers within the borehole at depth requires consideration of several critical constraints. First and foremost, all downhole samplers must fit within the inner diameter (ID) of the slick steel casing (tubing) used for CORKs. Typically, a $11.4 \mathrm{~cm}$ (4.5 inch) outer diameter (OD) pipe is used. This pipe is nested within a $27.3 \mathrm{~cm}$ (10.75 inch) OD and $25.4 \mathrm{~cm}$ (10 inch) ID casing. There have been many discussions about using a larger diameter casing for the CORK, which would provide more strength to the CORK and allow bigger packages to be deployed within the borehole; however, one restriction for using larger diameter casing is the diameter of the packers. For example, $11.4 \mathrm{~cm}$ (4.5 inch) OD casing has a $21.6 \mathrm{~cm}$ (8.5 inch) diameter packer, leaving a clearance of only $1.9 \mathrm{~cm}$ (0.75 inch) on either side of the packer. The use of larger tubing (5 or 5.5 inch OD) would require larger diameter packers, making the fit even tighter. Furthermore, the added strength afforded by the larger diameter casing is not significant (T. Pettigrew, pers. comm., 2010). Thus, downhole tools are restricted to a maximum of $8.9 \mathrm{~cm}$ (3.5 inch) in diameter, taking into account only one seal at the seafloor. In the case of multilevel CORKs, such as those intended for Expedition 336 with three distinct horizons, the deepest section requires that all samplers must have a diameter no larger than $6.3 \mathrm{~cm}$ (2.5 inch).

Another constraint for downhole instruments is that they must be able to withstand the temperature, pressure, and chemical conditions within the hole. At the sites currently instrumented, temperatures range from $3^{\circ}$ to $65^{\circ} \mathrm{C}$. Chemical conditions range from oxygenated seawater to highly altered fluids, from a $\mathrm{pH}$ of 7.8 to 12.2 , from gas poor to gas rich and supersaturated at standard temperature and pressure (e.g., aboard ship), and from oxic to reducing with measurable amounts of dissolved sulfide, methane, and hydrogen. These conditions deter- mine the suitability of materials for a particular deployment.

Other conditions are imposed by the nature of the CORK installation process. For example, every downhole package that has been recovered has been covered in pipe grease (typically a mixture of petroleum and metal [lead or zinc] powder). This grease is used generously between pipe joints during coring and CORK casing assembly. The grease is not restricted to the outside of downhole packages: it gets inside open cavities (e.g., Orcutt et al., 2011). In some cases, grease and sediment or rock fragments have been observed inside openings that act as cavities for drawing fluids into samplers. To date, no OsmoSamplers (1.2 mm ID) have been clogged with particles or grease from a borehole setting, but the presence of this grease should be taken into consideration for each experiment. For Expedition 336, nonmetallic and nonpetroleum-based lubricants are being considered.

Lastly, the sampling strategy and analytical program determine the length and number of samplers required. To date, only OsmoSamplers (described below) have been used to collect fluids in situ within boreholes. Typically, samplers are designed to draw $\sim 0.5 \mathrm{~mL}$ of sample per day over the course of several years. This flow rate is appropriate for postcollection processing of the fluids to resolve samples on a dayto week-long temporal scale, and the volume is large enough to measure chlorinity (via titration; requiring $0.05 \mathrm{~mL}$ ), major ions (via inductively coupled plasma-atomic emission spectroscopy [ICP-AES]; $0.05 \mathrm{~mL}$; $\mathrm{Ca}, \mathrm{Mg}, \mathrm{Na}, \mathrm{K}, \mathrm{Sr}$, and S), minor ions (ICPAES; $0.25 \mathrm{~mL}$; Sr, Li, B, Mn, Fe, and Si), and trace elements in seawater (inductively coupled plasma-mass spectroscopy [ICP-MS]; $0.1 \mathrm{~mL}$; V, Mo, Cs, Ba, Rb, Y, and $\mathrm{U}$ ). If a more ambitious sampling plan is desired, then more fluid can be collected or one could combine adjacent samples to include isotopic measurements for $\mathrm{O}, \mathrm{H}, \mathrm{S}, \mathrm{Li}$, and $\mathrm{B}$. The length of the deployment and desired sample rate result in sample tubing that is kilometers in length, and this can take up a significant length of vertical space inside the CORK casing, even with the tubing tightly coiled. The combination of osmotic pump and sample coils for a single typical downhole OsmoSampler package is $\sim 3-6 \mathrm{~m}$ in length.

We again stress here that instruments that are placed within the borehole should be deployed with the intention of leaving them for at least $3 \mathrm{y}$ and preferably $4-5 \mathrm{y}$. Such a long time span is required because each time a hole is drilled a considerable amount of seawater is introduced into the formation during the drilling process. The time required for the hole to return to in situ thermal and chemical conditions can 
take weeks to years (e.g., Wheat et al., 2003a, 2010b; Solomon et al., 2009). Even after in situ conditions return within the borehole, if the borehole is underpressured, seawater will flow into the borehole once the seals are removed during recovery of downhole instruments and the borehole must again recover; however, recovery is much quicker because the shear volume of seawater entering the hole is diminished relative to that introduced during drilling.

No fluid samplers or sensors that require electrical connection with the seafloor have been deployed in the borehole (only thermistor cables) because of the complexity of such a deployment, the lack of investigators wishing to modify their instruments to fit within the borehole, and the added expense of a cable. Complexities in deployment include last-minute potting of electrical bulkheads because the length of electrical cables cannot be determined until the hole is drilled and cleaned just prior to CORK deployment, and at least one connection must be made at sea. Bending a predesigned cable has not worked (i.e., bent thermistor cables usually result in poor or no data from the section below the bend). Another issue with deploying instruments that require an electrical connection from the drillship is that any data logger or unit used to access the electrical cable within the borehole must fit within the $11.4 \mathrm{~cm}$ (4.5 inch) diameter casing $(10.2 \mathrm{~cm} \mathrm{ID)} \mathrm{or} \mathrm{be} \mathrm{at-}$ tached to the wellhead. If the unit is not attached or buoyant, design constraints must account for it falling off the top of the well and disrupting other instruments and valves on the wellhead. A reasonable approach is to deploy a connector within a buoyant housing that can later be handled using a submersible.

In conclusion, the most significant issues with downhole fluid samplers and sensors are the confined space, consideration of appropriate materials, temporal length of the experiments, and difficulty and cost of providing communication and power.

\section{Downhole OsmoSampler}

\section{Design specifications}

The critical parameters for OsmoSampler design are outlined above. These parameters determine the number of membranes, the structural integrity of the packages, the types of sample coils, and the alignment of pumps and sample coils needed to achieve a variety of applications. We discuss each of these parameters below, with the caveat that the discussion is limited to what has been accomplished to date. There are many other possibilities, limited only by one's imagination.
OsmoSamplers use the osmotic pressure that is created across a semipermeable membrane by solutions of different salinity to continuously draw sample through a small bore $(1.2 \mathrm{~mm}$ ID) tubing (reviewed in Jannasch et al., 2004). This process is known as forward osmosis (FO) because it involves pumping a solution with the osmotic pressure gradient, rather than in opposition to it, as with a reverse-osmosis (RO) system (Cath et al., 2006; Wang et al., 2010) (Fig. F7; see also OSMO in CORK in "Supplementary material"). RO systems are used in traditional desalinization plants, where salt water is forced at high pressure through semipermeable membranes, effectively filtering solutes from seawater. The FO pumps that have been used in OsmoSamplers to date are based on a small-scale design that was initially developed for medical research purposes to deliver drugs to laboratory animals at a constant rate. The general equation for the flux of water $(J)$ across a semipermeable membrane using a single osmotic driving agent (solute) is

$$
J=K \cdot A \cdot(\sigma \Delta \pi-\Delta P),
$$

where water flow $(J)$ is directly proportional to permeability $(K)$ and the area $(A)$ of the membrane, $\sigma$ is the salt reflection coefficient and represents the ability of the membrane to reject the solute (approaches unity with an ideal semipermeable material), $\Delta \pi$ is the osmotic pressure differential driven by the difference in solute concentrations across the membrane as well as the type of solute used, and $\Delta P$ is the hydrostatic pressure differential between the intake and outflow of the system (Theeuwes and Yum, 1976). For an ideal FO system with negligible hydrostatic pressure, zero solute concentration in the feed (i.e., distilled water) solution, and an ideal semipermeable membrane, the flux of water through the system is governed only by the physical properties of the membrane and the osmotic pressure of the solute:

$$
J=K \cdot A \cdot \pi
$$

Thus, osmotic pressure is used to draw fluids into the small-bore tubing that is connected to the distilled water reservoir of the osmotic pumps. Small-bore tubing is used because the combination of the small bore and slow flow rate minimizes dispersion, resulting in pluglike flow (Jannasch et al., 2004). Upon completion of the deployment, the sample coil is disconnected from the pump. Lengths of tubing (typically $\sim 1 \mathrm{~m}$ ) are cut, and the fluids are discharged out of these discrete sections into sample vials; a continuous sample collection device cannot be used because dispersion within the tubing during extraction will "homogenize" the sample and decrease 
temporal resolution. Time stamps for the individual samples are calculated given the start and end dates and number of discrete samples (assuming constant lengths/volumes of tubing cut), provided the temperature is constant for the deployment. All of the other variables are constrained through the pump and membrane design.

\section{Membranes and pumps}

At the crux of all osmotic pumps (Fig. F7) is the membrane that allows water to flow through it, yet prevents the transfer of ions. Many materials can be used for a membrane. These materials can be commonly found in a local hardware store where $\mathrm{RO}$ products are sold. However, the key to a good membrane material is longevity and reproducibility at depth and temperature.

We have had excellent success with cellulose acetate (CA) membranes sold by Alzet. These membranes are rigid and commonly used in pharmaceutical studies for drug-delivery mechanisms. Thus, these membranes are subject to strict quality control measures to ensure a uniform product. This product also has a well-defined response to temperature and is not influenced by oceanic pressure. Although these membranes come in several materials, they are available in two sizes. In contrast, RO thin-film membranes come in a variety of sizes, are paperlike in texture, and can be acquired in rolls or sheets from local water agencies. RO membranes are not as uniform as the Alzet membranes, but some types of RO membranes pump orders of magnitude faster for an identical surface area. The reason for the reduced pump rate of the Alzet membrane is that the thickness of the semipermeable (active) layer is greatly increased. In addition to greatly reducing the pump rate, it makes the membrane self-supporting. In contrast, thin-film RO membranes experience solvent fluxing into the porous support layer (often paper) and dilute the solute with time, reducing the osmotic driving force and the pump rate. This effect is called internal concentration polarization (Gray et al., 2006). The decision to use either RO or Alzet membranes is typically dictated by the volume of fluid needed versus the length of the deployment, with multiyear samplers necessitating the use of the nonvariable Alzet membranes.

An osmotic pump consists of a membrane that separates a freshwater reservoir from a salty reservoir (Jannasch et al., 2004; Wheat et al., 2000). As described above, the rate of water transferred across the membrane is a function of the chemical gradient, temperature, pressure, type of membrane material, and surface area of the membrane. Osmotic pumps rely on a chemical gradient that is defined by dis- tilled water on one side of the membrane and saturated salt on the other side. Noniodized table salt is used on the saturated salt side because it has a high solubility (greater gradient) and is inexpensive, easy to purchase, and nontoxic. Noniodized salt is preferred because it appears to pour more easily. If one were to use a different salt with a lower solubility, the pump rate would be less, given all of the same parameters above. Thus, to maintain a uniform pump rate during a deployment, the sample coil is filled with distilled water and enough salt is added to the reservoir opposite the distilled water such that at the end of the deployment some crystalline salt remains. It is important to make sure that Alzet membranes are completely filled with salt and that osmotic pumps are deployed vertically to keep salt crystals against the membrane (i.e., a tilted pump may allow the salt to settle away from the membrane, which will affect the ionic gradient if a freshwater lens forms in the pump). Increases in temperature usually increase the rate of pumping, as diffusion is quicker at higher temperatures.

Lastly, pressure can be a factor with some pump systems. An increase in pressure sometimes increases the pump rate of RO systems. We believe this results from the removal of air from spaces within the RO membrane because upon return to the sea surface these membranes continue to pump at the in situ rates. Typically, we have designed OsmoSamplers with Alzet membranes because there is not a strong demand for $>0.5 \mathrm{~mL}$ of sample per day and enough membranes can fit within the allotted diameter of the pump to get the desired pump rate for a given temperature. Typically, pumps use 12 Alzet 2ML1 membranes for deployments at seafloor temperatures, providing $\sim 0.7 \mathrm{~mL}$ of sample per day, or $250 \mathrm{~mL}$ per year (this volume fits easily within one $305 \mathrm{~m}$ long spool of $1.19 \mathrm{~mm}$ ID tubing).

In contrast, some RO membranes (47 $\mathrm{mm}$ diameter) pump fluids at a rate of $50 \mathrm{~mL}$ per day. The primary problem with RO membranes is the internal concentration polarization effect, which is caused by a buildup of solute in the support layer over time, reducing the osmotic pressure gradient and the pump rate (Gray et al., 2006). Thus, determining time stamps for individual samples is less certain. There is currently only one commercially available FOspecific membrane, produced by Hydration Technologies Inc., and it has performed well when used in FO systems (Cath et al., 2006). Wang et al. (2010) conducted experiments with an alternative to the commercial membranes by synthesizing doubleskinned CA membranes that minimize the internal concentration polarization by preventing solute from entering the support layer. We have not, as yet, 
applied thin-film FO-specific membranes to OsmoSampler products, but we are currently experimenting with thin-film designs using $\mathrm{RO}$ and $\mathrm{FO}$ membranes.

Another key issue with osmotic pumps is the mechanism that seals them from the outside, except for the intake where sample tubing is attached and the outflow where saturated salt water exits. To make such sealed environments, a combination of O-rings and two-part epoxy has been used. If O-rings are used, two are suggested, with one serving as a backup. A potential problem with two O-rings is the presence of air between the two O-rings. Constructing the pumps under water in a large tub or garbage can will eliminate this concern. The Expedition 336 pumps will use only one O-ring, avoiding underwater construction, but the O-ring has a substantial diameter to maximize the sealing surface. Epoxies are effective, especially for holding Alzet membranes in the pump housing. For deployments at $<40^{\circ} \mathrm{C}$ a two-part polyurethane compound (Fluid Polymers; HMP-60) has had great success. However, at higher temperature (certainly at $64^{\circ} \mathrm{C}$ ), this epoxy becomes soft and pliable and flows. Hysol ES1902 is a suitable two-part epoxy for warm $\left(>50^{\circ}-80^{\circ} \mathrm{C}\right)$ environments. Early samplers relied solely on epoxy, but recent deployments include an O-ring and epoxy design to provide a redundant sealing mechanism for Alzet membranes. In contrast, $\mathrm{RO}$ membranes, because of their paperlike consistency, are held in place with an O-ring seal with support grids on both sides of the membrane.

One must also consider what material to use to hold and protect the membranes while maintaining a leak-free system. Polycarbonate and translucent polyvinyl chloride (PVC) are typically used for this purpose because both materials are easy to machine and epoxy readily seals to both. Polycarbonate is used for cool $\left(<40^{\circ} \mathrm{C}\right)$ oxygenated or mildly reducing environments. However, polycarbonate should not be used in reducing environments with hydrogen sulfide. Hydrogen sulfide impregnates polycarbonate in seawater, making it brittle. Once retrieved, hydrogen sulfide will degas and the polycarbonate will return to its initial state, flexible but clouded. Therefore, PVC is used for reducing environments. Clear PVC tubing is not readily available in many sizes; however, individual production runs are available. Clear PVC allows one to observe conditions within the pump and track the status of O-rings during assembly.

As with the membranes, the pump assembly can be held together with O-rings and machined grooves or a combination of O-rings and epoxy. If epoxy is used, the pump cannot be modified or refurbished.
One also must be concerned with getting a complete seal with the epoxy and ensuring the epoxy is flexible enough to withstand the potential beating that OsmoSampler packages take while being deployed. Many pumps have been deployed using only epoxy without incident, but a double O-ring seal is suggested for deployments at temperatures of $>40^{\circ} \mathrm{C}$.

Lastly, we do everything possible to protect the membrane from ambient water (e.g., adding extra spools of sample tubing). However, there are times when one cannot retrieve the sampler on time and sample overflows from the coiled tubing to the freshwater reservoir. It is always wise to check the salinity of this reservoir following recovery to determine whether it has been compromised. If seawater reaches the distilled water reservoir, salt from the fluid being sampled increases in the freshwater reservoir because only water passes through the semipermeable membrane. The presence of salts in the freshwater reservoir decreases the salt gradient, slowing the pump rate. Furthermore, ambient fluids contain microbes and dissolved chemical species that can be detrimental to membrane integrity. Such was the case for one deployment in ODP Hole 1026B. Borehole fluids (and potentially microbes) dissolved several membranes completely, stopping the pump.

\section{Strength elements and structure}

Considering the demands of deployment and recovery operations, downhole packages must be well protected and have a strength member to provide support. Several options have been tried. Initially, OsmoSampler packages were add-ons and were designed to be compatible with the existing CORK design and modes of deployment and recovery. To maintain continuity of the thermistor cable, initial OsmoSampler packages were attached to the cable. In some cases, OsmoSampler packages were attached mid-cable. These noncentered deployments were potentially problematic. Other packages were designed so that the cable could slide down the middle of individual OsmoSamplers. As a result, OsmoSampler packages were placed in the middle of the thermistor cable in ODP Hole 949C and near the bottom of the thermistor cable in ODP Holes 1024C, 1025C, 1026B, 1027C, and 1200C (Shipley, Ogawa, Blum, et al., 1995; Davis, Fisher, Firth, et al., 1997; Salisbury, Shinohara, Richter, et al., 2002). In each of these cases the strength member consisted of a stainless steel rod or tube at the center and a PVC or polycarbonate tube on the outside for protection.

For added strength, OsmoSamplers were placed in steel pipes during Leg 205, with their intakes extending from the ends of the pipe; however, several issues arise with steel tubing. First, steel oxidizes, coating 
the samplers with rust and making it more difficult to obtain a "clean" sample when removing and cutting up sample coils. Second, few shops can machine long, straight pipes, and transport requires cranes and forklifts.

Given the difficulties with steel tubing, we suggest using a $1.27 \mathrm{~cm}(0.5 \mathrm{inch})$ diameter stainless steel rod as the strength member. This rod may include a groove that allows small-bore tubing to be placed and protected so that it can connect to another part of the package or discharge into a desired area. OsmoSamplers fit around this strength member with a snug-fitting outer protective shell of polycarbonate or clear PVC. Galvanized shackles are then connected to the stainless steel support rods to connect to other OsmoSampler packages, plugs, Spectra cable, or sinker bars. Shackles will be discontinued during Expedition 336 because $1.25 \mathrm{~cm}$ thick shackles (required for strength) are too large for small-borehole conditions. Instead, a novel pin-locking system has been developed and will be deployed. OsmoSampler components were assembled and placed within a single PVC or polycarbonate housing for protection. In some cases, the outer diameter of the pump was designed as the outer protection; thus, assembly is modular, with separate protective housings for different parts of the sampler (Fig. F8).

\section{Sample coils}

OsmoSamplers rely on small-bore tubing for nonturbulent (dispersive), pluglike flow (Fig. F7). Two sizes of tubing have been used: 0.8 and $1.19 \mathrm{~mm}$ ID. The larger diameter is more common because it holds more water per unit length $(0.50$ and $1.11 \mathrm{~mL}$, respectively, for a $1 \mathrm{~m}$ long section). The larger diameter tubing has been purchased in bulk from Professional Plastics (Elosia 800-338-2011). Tubing is purchased as a continuous roll that is $305 \mathrm{~m}$ (1000 ft) long with a $1.19 \mathrm{~mm}(0.047 \mathrm{inch})$ ID holding $339 \mathrm{~mL}$. The OD for fluorinated ethylene propylene (FEP) tubing is $2.0 \mathrm{~mm}$ (0.079 inch), and for copper it is $1.8 \mathrm{~mm}$ (0.071 inch). The purchased material is spooled on PVC spools with a lathe or any variable-speed motor. These spools slide over the internal stainless steel strength rod and fit within the protective outer tubing. It takes $\sim 2 \mathrm{~h}$ to spool a $305 \mathrm{~m}$ long coil by hand or $30 \mathrm{~min}$ on a lathe.

Before deployment, all sample spools are filled with distilled water. A peristaltic pump is used to inject water into the coil to make sure there are no leaks, and then $10 \%$ hydrochloric acid is pumped into the coil to remove any trace metal contaminants. This acid remains in the tubing for $\sim 1$ week. Longer storage is problematic because air bubbles will form in the tubing, which drastically increases the resistance when flushing the coil, requiring a much slower pump rate. Distilled water is pumped into the coil to remove the dilute acid $\sim 1$ day before assembly. Coils filled with distilled water are stored at a constant temperature to avoid the production of air bubbles. Filling the coils with degassed distilled water can alleviate this concern if the coils are deployed within days. Air bubbles greatly restrict flow and are an issue for shallow deployments. For deep deployments, air bubbles will dissolve at depth, but the volume of these air bubbles is replaced with seawater at the intake. This seawater influx, if substantial, could affect the calculated sample time stamps. Copper coils are filled with distilled water to check for leaks and are then flushed with distilled water before assembly.

Any number of coils can be used, depending on the analytical program and duration of the deployment. Coils are attached with "Upchurch" flangeless compression fittings ( $1 / 4-28$ threaded polyether ether ketone [PEEK], or Delrin, nuts with a $1 / 16$ inch ID) using readily available nuts, ferrules, and unions. Such fittings must be tight, but not so tight as to pinch off the tubing at the ferrule. Practice with a connection and tighten by hand as much as possible. Release the connection and check to verify that there is not a significant constriction. Furthermore, it is important to check the tubing for any kinks or drastic bends that may crimp the tubing. We tighten fittings as tight as possible and then push water with a syringe through the connected coils. This confirms that the union and fittings are not leaking and that there is no significant constriction. Seven $305 \mathrm{~m}$ long coils have been attached to a single pump for a 5-6 y deployment. The connection to the pump is always supported with PTFE tape to ensure that the nut will not unscrew at depth. Likewise, all fittings at the pump are wrapped in PTFE tape to minimize the potential for leaks because different materials have different thermal expansion coefficients. PTFE tape can be used on any connection.

\section{Geochemical, microbial, and hydrologic configurations}

The combination of pumps with different numbers and types of membranes and sample coils provides for a range of possible OsmoSampler packages (e.g., Fig. F2; see also OSMO in CORK in "Supplementary material"). The standard package contains one pump and a number of PTFE coils. This type of sampler is ideal for ship- and shore-based analysis of the major and minor ions in seawater and, more recently, for microbiological characteristics. Unfortunately, PTFE is permeable to gas exchange with the formation fluid. Thus, if the gas concentration (e.g., carbon dioxide, oxygen) changes during the deploy- 
ment, only the most recent composition will be retained.

The gas package is ideal for maintaining concentrations of dissolved gases. This package uses copper tubing instead of PTFE. Similar to the standard package, the gas package uses only one pump with a number of copper coils connected by fittings and unions. One issue with such small-bore copper tubing is the ability to make a clean cut. Dental tools are ideal for opening the tubing after an imperfect cut. Following recovery, the ends of the coils are crimp sealed for shore-based analysis if analysis is not possible at sea. Freezing the crimped coils can keep the solution from mixing; the expansion of water upon freezing does not break this small-bore copper tubing. Note that highly gas saturated environments may lead to an overpressure in the OsmoSampler sample tubing, which can cause sample smearing or, in the worst case, complete loss upon recovery. The use of valves to close OsmoSampler coils prior to recovery can maintain in situ pressures and gas concentrations (e.g., Lapham et al., 2008) and were included in the downhole package deployed in Hole 948D.

Another class of OsmoSampler includes the acidaddition and BioOsmoSampling System (BOSS; Girguis et al., 2008) packages. Both packages comprise (from bottom to top) a sample coil, a lower pump, a second coil, a T-connector, a series of sample coils, and a second pump. The lower pump pulls fluids into the lower sample coil, acting as a standard OsmoSampler, and the saturated salt fluid is expelled into the second coil to disperse the coil contents. In the acid-addition OsmoSampler package, this second coil is filled with diluted, subboiled hydrochloric or nitric acid, often including a tracer (e.g., a rare earth element) to document the extent of dilution. Thus, the lower pump pushes the acid out and into the T-connector, which has one branch open to the borehole (sample intake) and the other branch attached to the upper series of sample coils. These coils are attached to a second pump that pumps at a rate that is at least four times faster than the lower pump. Thus, coils above the T-connector capture borehole fluids from the T-connector's sample intake as well as acid expelled by the lower pump, acidifying the sample in situ. This preserves the sample for trace metal analysis and prevents microbial oxidation and mineralization within the sample tubing. This process also may dissolve small, suspended particles that are incorporated into the sample stream. The BOSS package is configured identically to the acid-addition package, except a biocide (e.g., ammonium sulfate, glycerol, or mercuric chloride) is used in the second coil instead of dilute acid, preserving samples for microbiological analysis.

The Flow-through Osmo Colonization System (FLOCS) (Orcutt et al., 2010) package is designed to use an osmotically driven pump to slowly pull formation fluid into microbial colonization devices for in situ experimentation. The term "FLOCS" refers to a series of chambers filled with various minerals and other substrates for examining microbial growth under controlled conditions. These flow-through chambers are connected to the intake of PTFE sampling coils and an osmotic pump. Chambers are designed with minimal excess pore space so that borehole fluids flow through the chambers and into the sample coils. These coils allow one to characterize reactions within the chambers by comparing results to those from a standard package.

The enrichment package is a combination of the FLOCS and acid-addition packages. This package is essentially the same as the acid-addition package, except the FLOCS experiment is positioned between the T-connector and the upper series of sample coils. The coil above the first pump is filled with enrichment material instead of dilute acid. The enrichment solution could contain any number of substances, including isotopically labeled carbon, amino acids, nutrients, sugars, or any rate-effecting substance that will mix with borehole fluids in the FLOCS chamber (Fisher, Wheat, et al.).

A tracer package is used to introduce a chemical tracer into the borehole environment at a constant rate to examine fluid mixing within the borehole. This package consists (from bottom to top) of a series of sample coils, a single pump, and a similar number of additional sample coils. Basically, the tracer package is a standard package with coils attached to the salt water outflow of the pump. Like the acid-addition package, saturated salt water is pumped into these upper coils, expelling the fluid, which contains some type of tracer. A variety of tracers can be used; however, the tracer solution should be many orders of magnitude more concentrated than what occurs naturally within the formation. Historical deployments used $\mathrm{Cs}, \mathrm{Rb}$, and rare earth elements (Fisher et al., 2005). Other potential tracers include but are not limited to $\mathrm{SF}_{6}$, labeled isotopes, and fluorescent microspheres.

Lastly, a flowmeter package has been developed for documenting fluid flow speeds and direction within a borehole (Jannasch et al., 2003; Solomon et al., 2009). This package uses a series of three standard packages and one tracer package. Four intakes are positioned within a machined titanium solid stock with two perpendicular crossing holes. Intakes are positioned near the ends of these holes, with the 
tracer injected in the middle where the two holes intersect. Thus, the presence and concentration of the tracer at the various intakes is a function of the direction and rate of flow through the system.

Each of these OsmoSampler packages includes space for a self-recording temperature sensor. Because of the pump design, the only factor determining flow rate is temperature. Two different temperature units have been used at full ocean depth. The Antares logger (Titanium $1857 \mathrm{C}$ MTL, 16 byte) has a resolution of $0.002^{\circ} \mathrm{C}$ and can be purchased with a low $\left(0^{\circ}-\right.$ $\left.45^{\circ} \mathrm{C}\right)$ or high $\left(>40^{\circ} \mathrm{C}\right)$ temperature range and with an extra battery for a 5 y deployment. Onset (U12015 titanium, 12 byte) also sells a temperature unit with a 5 y lifetime, but the resolution is $0.1^{\circ} \mathrm{C}$ at lower temperatures $\left(<30^{\circ} \mathrm{C}\right)$ and $0.3^{\circ} \mathrm{C}$ at $\sim 60^{\circ} \mathrm{C}$ (Fisher, Wheat, et al.).

\section{Weights, rope, and plugs}

A complete downhole string generally comprises (from bottom to top) a sinker bar, a number of OsmoSampler packages, a plug, Spectra cable, possibly a middle sinker bar, and a top plug. The weight of the bottom sinker bar deployed from the drillship is typically $91 \mathrm{~kg}(200 \mathrm{lb})$ in seawater. Together with the weight of the OsmoSampler packages, plugs, and middle sinker bar, the weight of the string is $\sim 200 \mathrm{~kg}$ in seawater (400-500 lb). The sinker bar not only acts as a useful guide to position the rest of the string in the hole, its weight also allows one to detect when the string is released from the wireline mechanism during deployment. Because of the weight of the ship's wire, $200 \mathrm{~kg}$ is about the limit for detecting the release of the string in good weather (minor heave). For submersible-aided deployments, the bottom sinker bar weighs less (68 kg [150 lb]) because of handling issues on deck and on the seafloor. In contrast, middle sinker bars do not weigh as much $(5-50 \mathrm{~kg})$, serve to help pull down the Spectra cable, and are typically $5 \mathrm{~cm}$ in diameter.

Downhole plugs are generally made of stainless steel and seal with an O-ring surface (Fig. F8). Because of the confines of the well and the desire for multiple levels, most seal surfaces can accommodate only one O-ring. Downhole plugs are generally $10 \mathrm{~kg}$ in water. The weight of the plug and the materials hanging below need to exceed the buoyancy force in crust that is overpressured relative to hydrostatic. On ridge flanks this could require several hundred kilograms. In subduction zones this could require even more weight or the necessity of a latch-type plug at the seafloor. Thus, depending on the environment, the surface latch may be a simple O-ring gravity seal or an O-ring latch seal. The only concern with a latch is the potential for failure due to corrosion and the inability to access the borehole. Several configurations have been used for top plugs, each requiring different tools for retrieval (see "CORK-IIs and LCORKs").

Spectra cable is made from Spectra Fiber 900/1000/ 1200 (Puget Sound Rope), an ultrahigh-molecular weight polyethylene fiber. Honeywell Spectra is used because it is buoyant (or at least neutrally buoyant) in seawater, strong, and durable in a variety of chemical and thermal conditions. It withstands temperatures of $65^{\circ} \mathrm{C}$ in reducing conditions and fluids with a $\mathrm{pH}$ in excess of 12 . Spectra cable $(0.95 \mathrm{~cm} \mathrm{[3/8} \mathrm{inch],}$ with a minimal tensile strength of $6,300 \mathrm{~kg}$ $[13,900 \mathrm{lb}])$ is carefully measured by the manufacturer; however, the rope stretches with weight. Once the rope is stretched under load (>200 kg, which is the weight of a typical string during deployment), it maintains this new length, $2 \%$ longer than the length purchased from the manufacturer.

\section{Guiding principles for seafloor systems}

Seafloor samplers and sensors do not have the myriad restrictions and concerns that must be considered in the design of downhole systems. For example, since these instruments are bathed with cold seawater, corrosion and gas exchange issues are minimal. Also, there is no space restriction at the seafloor, allowing large instruments to be deployed with a submersible or on an elevator. An elevator is a platform that allows many or heavy items to be placed on the seafloor. Elevators are released from the ship near the target location. After they descend, they are located by submersible and moved into position near the CORK. Tools, samplers, and instruments from the elevator are used and replaced. When work is completed the elevator's drop weights are released, allowing it to float to the surface. Thus large and complex instruments can and have been deployed to sample fluids that discharge naturally from overpressured holes in permeable crust and those that are extracted through umbilicals that bisect a hydrologic horizon of interest. The type, number, and size of umbilicals have differed through the years as interests and goals have changed. Similarly, valve and mating systems for connecting instruments to umbilicals have changed. Below, we describe the different umbilicals and valves and the evolution of both. Then we describe a number of sensors and samplers that have been attached to these valves and some that have been lowered into boreholes using underwater vehicles. 


\section{Seafloor systems}

\section{Umbilicals}

Umbilicals are lengths of tubing that terminate at the seafloor and at depth, allowing fluids to be transported from the subseafloor to the seafloor. An umbilical can consist of a single length of tubing or a collection of tubing bundled in a hard plastic sheath for protection. The initial geochemical tubing (umbilical) was thin-walled PTFE tubing (Davis, Mottl, Fisher, et al., 1992). The umbilical was designed to act as a conduit for fluids to flow from depth and ascend without contacting the mild steel casing, minimizing artifacts and providing a pristine formation fluid sample from the hydrologic horizon of interest. However, the wall of the PTFE tubing was too thin; the tubing collapsed when it was attached to the thermistor cable, and it was not robust enough to withstand handling on the rig floor during deployment.

Hardened armored tubing has been used on all CORKs for geochemical analysis since Leg 205. At those sites where the hydrologic zone of interest ends in sediment (e.g., Hole 1255A), umbilicals terminate in miniscreens placed within a carbolite pack, which prevents sediment particles from clogging the screens. Carbolite packs are permeable $(\sim 2 \times$ $10^{-10} \mathrm{~m}^{2}$ ) and are made from relatively nonreactive ceramic material (aluminum oxide ceramic with a grain size of $400-600 \mathrm{~mm}$ and a porosity of $\sim 30 \%$ ) (Mikada, Becker, Moore, Klaus, et al., 2002). This material is strapped around a screened portion of the casing, allowing water to flow from a larger area into the carbolite pack and finally into the miniscreen. An inflatable packer is then used to seal off the hydrologic horizon from the remainder of the hole. This design allows for multiple horizons to be sampled, provided packers and sediment seal the hole. This CORK design also leaves the borehole open for instruments.

A variety of tubing sizes and types have been used on CORK-IIs to access seafloor horizons for fluid sampling. Most of this tubing is made of stainless steel, and the diameters are chosen depending on the hole and desired sampling program. The first consideration in umbilical design is to assess whether the formation is overpressured or underpressured relative to hydrostatic. The former produces a free-flowing system, provided that the formation is permeable. For this situation, larger diameter tubing is desired $(1.27 \mathrm{~cm}[0.5 \mathrm{inch}])$, minimizing the impedance of natural flow. The latter requires a pump to draw fluids up the tubing. If a mechanical pump is chosen to extract fluids from depth, then large $(1.27 \mathrm{~cm})$ tubing is desirable to reduce frictional drag during me- chanical pumping (e.g., backpressure). However, small-bore tubing is desirable if the intent is to collect fluids with an OsmoSampler at the surface. Stainless steel tubing with $0.32 \mathrm{~cm}(0.125$ inch) OD and $0.175 \mathrm{~cm}$ (0.069 inch) ID was used for an umbilical deployed during Expedition 301 to minimize the volume of fluid in the tubing, allowing osmotic pumps to recover fluids in a reasonable amount of time.

The observed effect (i.e., concentration) of extended exposure of borehole fluids to mild steel casing on fluid composition (e.g., iron, $\mathrm{H}_{2}, \mathrm{H}_{2} \mathrm{~S}$ ), and potentially on microbial community compositions, resulted in the use of an armored tubing with an ethylene tetrafluoroethylene (ETFE) fluoropolymer wetting surface. Armored ETFE was chosen because it is nonreactive. It was first used in IODP Hole U1301B $(1.2 \mathrm{~cm}$ OD). To minimize contamination, titanium tubing connections, valves, packer pass-throughs, and miniscreens were used. Unfortunately, this line failed to produce significant flow, despite substantial mechanical pumping, possibly because of damage to the umbilical during deployment. New CORK installations during Expeditions 327 and 336 are and will be equipped with multiple stainless steel and ETFE umbilicals to service a variety of fluid-sampling needs and provide redundant systems.

The desired configuration for Expedition 336 is a single $1.27 \mathrm{~cm}$ (0.5 inch) diameter armored ETFE tubing and two stainless steel tubes $(0.32 \mathrm{~cm}$ [0.125 inch] and $0.634 \mathrm{~cm}$ [0.25 inch]) for each depth horizon. The smaller stainless steel tubes are desired because the boreholes are believed to be underpressured relative to hydrostatic. Thus, when the sample valve is opened, seawater will flow naturally into the tubing and descend to the formation. Thin-film OsmoSamplers (see "Design specifications") will be attached to the small-diameter tubes, minimizing the residence time that fluids spend within the umbilical tubing. The larger bore ETFE tubing is designed for chemical and microbiological experiments that require large volumes of fluids at discrete sample intervals. This larger tubing greatly minimizes frictional drag and the residence time that fluids spend within the tubing relative to a slower osmotic pump.

\section{Valves and bays}

Originally, the valves and tubing connecting seafloor samplers and sensors to the horizon of interest consisted of a ball valve with a male Aeroquip quick-disconnect connector (complete assembly: number FD72-1000-08-10; female half: number FD72-100108-10; male half: number FD76-1002-08-10) (Figs. F9, F10; see HANDLE in CORK in "Supplementary material"). However, Aeroquip valves are problem- 
atic; they are often difficult to connect, and without making in situ real-time measurements (e.g., temperature and oxygen) one is never sure that the system is fully coupled. Even today, discussion continues regarding the quality of data and the potential for problems with this connection.

As issues related to the Aeroquip connector grew, CORKs deployed during Expedition 301 included a series of valves and a unique sample distribution system (Fig. F4; see GUIDE in CORK in "Supplementary material"). This system accepts interchangeable plates upon which samplers can "sip" (for overpressured systems) or pump fluids from the formation. Some of the stainless steel umbilical tubing is $0.32 \mathrm{~cm}(1 / 8 \mathrm{inch})$ OD with an ID of $0.175 \mathrm{~cm}(0.069$ inch), allowing seafloor OsmoSamplers to recover fluid within a reasonable period of time. OsmoSamplers and other samplers are attached to the wellhead using a metal plate that guides sample intakes over titanium fittings on the wellhead (Fisher et al., 2005).

The plate system of sample access is sometimes difficult to deploy, and successful deployment is dependent on the pilot. Because of this difficulty and those caused by using the Aeroquip connector, a new sample connector was developed for Expedition 327. This connector relies on a double O-ring seal. The O-rings reside in an easy-to-manipulate handle that is in position only when the O-rings are clearly sealed in the base (Fig. F5; see HANDLE327 in CORK in "Supplementary material"). The base, made from ultrahigh-molecular weight polyethylene, houses the valve and the sample port. This housing guides the sample handle to and over the $1.27 \mathrm{~cm}$ (0.5 inch) diameter PEEK tube, which is an extension of the umbilical. This configuration also removes the necessity of the large plates required for Expedition 301 CORKs, allowing flexibility in package design (e.g., deployment of samplers and experiments in a milk crate), which can be hung from a series of hooks below the valves or from cut-outs in the bulkhead gussets. These new connections were first deployed on CORKs deployed in Holes U1362A and U1362B during Expedition 327. The new connections will also be used during Expedition 336, but the PEEK ID will be identical to the umbilical ID and the void space in the handle will likewise maintain the same ID.

With the addition of umbilicals for geochemical and microbial sampling, the CORK wellhead was modified to fit extra valves and make room for sampling systems. The wellhead was transformed during Leg 205 to have partitions (bays) around the central strength member. During Expedition 301 the partitions were designated for pressure, geochemistry, and microbiology sampling, but any bay can be used for any type of scientific measurement or collection. This partitioning allowed different groups to design sampling capabilities without affecting others.

Presently the bays are $198 \mathrm{~cm}$ in length, and they will be extended during Expedition 336 another $60 \mathrm{~cm}$ to accommodate new samplers that will be deployed from the drillship. Samplers must fit within a radius of $\sim 76 \mathrm{~cm}$ extending from the $11.4 \mathrm{~cm}$ OD inner mandrel (strength member) to accommodate the diameter of the wireline camera system on the JOIDES Resolution. No outward radial restrictions apply once the wellhead is on the seafloor.

\section{Seafloor sampling and sensor systems}

Sampling and sensor systems on the seafloor rely on the umbilical and valve systems to obtain borehole fluids from specific depth horizons. If the horizon at the end of the umbilical is permeable and overpressured relative to hydrostatic, fluid will naturally flow up the tubing when the valves at the seafloor are opened. In contrast, if the horizon is underpressured, a pump (mechanical or osmotic) is required to pull formation fluid up through the umbilical tubing to a sampler on the seafloor. For example, formation fluids have been flowing from the décollement, ascending the umbilical in ODP Hole 808I, and discharging at the seafloor for the past several years. Thus, all that is needed to collect these fluids is a sampler with a small snorkel (inlet).

An example of a seafloor collection device that tapped into an umbilical or wellhead valve is the "BioColumn," a series of microbiological and geochemical samplers designed to take advantage of the free-flowing system in ODP Hole 1026B (Cowen et al., 2003) (Fig. F11A). The BioColumn channeled borehole fluids past temperature and flow sensors, through particle filters ( $>0.4 \mu \mathrm{m}$ pore size), and into an organic compound-scavenging resin column to collect samples for fluid composition, biomass, DNA, and lipid analysis. BioColumns were deployed for days to $1 \mathrm{y}$, with remarkably constant, unassisted flow rates of $\sim 4.4-5.4 \mathrm{~L} / \mathrm{min}$ (Cowen et al., 2003; Cowen, 2004).

However, the greatest disadvantage of the initial BioColumn is that the fluids collected from the top of the borehole must flow past $295 \mathrm{~m}$ of mild steel casing. The extent to which the fluids are altered by interaction with casing, cement, and other drilling remnants has been documented by sampling fluids that vented from the borehole after the data logger was removed and the borehole was well ventilated (Wheat et al., 2004). Fluids that flowed unrestricted through the steel casing and out the $10.6 \mathrm{~cm}$ diameter opening at the top of the CORK into seawater 
were contaminated with high dissolved and particulate concentrations of several metals, including iron (Wheat et al., 2004). This leads one to wonder if the surface of the iron liner could support a biofilm community that could contribute to the cellular biomass and molecular diversity observed in the ODP Hole 1026B fluid and BioColumn samples, considering that the BioColumn restricts flow to $\sim 4.8 \mathrm{~L} / \mathrm{min}$, with a maximum temperature of $59^{\circ} \mathrm{C}$ at the CORK valve (Cowen et al., 2003).

Submersible positive displacement pumps were developed to draw fluids from subbottom horizons using the umbilical system at rates sufficient to deliver tens of liters of fluid within one to several hours. Initially, pumps were downstream of the samplers, which limited sampling and plumbing options and made the pumps more susceptible to contamination from ambient bottom seawater. Subsequent use of a PTFE and titanium pump head that is magnetically coupled to the motor drive improved performance and increased versatility (i.e., pump draws fluid up the CORK's umbilical and then pushes fluid through or past sensors and samplers). Pumps are connected to the CORK fluid delivery line with an Aeroquip connector on CORKs deployed prior to Expedition 327 and with the new O-ring-based connector design on CORKs deployed during Expedition 327 or later. It is essential to evaluate the seal in situ, if possible, using available information such as temperature, current to the pump, and the pump's programmed and actual revolutions per minute.

These fluid pumping systems have been used effectively with both in-line samplers (e.g., GeoMICROBE sled) and end-of-line samplers. The latter include in situ filtrations and the filling of large-volume bag samplers (e.g., Wommack et al., 2004) (Fig. F11B). Such large-volume in situ filtration systems have an autonomous mode that can be connected to the wellhead for several days of continuous operation. Another mode places the pump on the submersible. The sampler can be transported to the seafloor on an elevator or on the submersible. Alternatively, pump systems can have their pumped effluent directed to an exit port that can be accessed by a variety of conventional fluid samplers (e.g., Ti-majors fluid samplers, gas-tight fluid samplers, and syringe samplers).

The GeoMICROBE sled couples this water-collecting capability with a variety of in-line sensors (e.g., temperature, fluid flow, and in situ electrochemical analyzer; Fig. F11C) (Cowen et al., unpubl. data), including voltammetric measurements with solid-state gold/amalgam $(\mathrm{Au} / \mathrm{Hg})$ voltammetric (micro)electrodes (e.g., Luther et al., 2008; Glazer and Rouxel, 2009). In voltammetry, current is measured while scanning a voltage range, allowing simultaneous de- tection of multiple chemical species (analogous to varying wavelength and measuring absorbance with spectroscopy). Many redox species can be characterized, including $\mathrm{O}_{2}, \mathrm{Mn}^{2+}, \mathrm{Fe}^{2+}, \mathrm{H}_{2} \mathrm{~S} / \mathrm{HS}^{-}, \mathrm{S}_{2} \mathrm{O}_{3}{ }^{2-}, \mathrm{S}_{4} \mathrm{O}_{6}{ }^{2-}$, $\mathrm{S}^{0}$, and aqueous FeS and Fe(III) clusters. These in situ measurements are made with an in situ electrochemical analyzer (ISEA) (Analytical Instrument Systems, Inc.). A titanium pressure case houses the analyzer, which consists of a potentiostat, an eight-electrode multiplexer, and an internal computer with $8 \mathrm{~GB}$ flash memory. Recent improvements to the ISEA include the capability for simultaneous $\mathrm{pH}$, Eh, temperature, and optical oxygen sensor data collection and a stepper motor to control micromanipulators, valves, and pumps. Waterproof bulkhead connectors (Subconn, Inc.) allow cabled connection to an external power source and RS-232, RS-422, or ethernet communication for real-time measurements (e.g., via submersible) or unattended preprogrammed data collection (e.g., via GeoMICROBE sled). The new ISEA also incorporates a controller that is capable of booting into a stand-alone data logging configuration, utilizing a low-power sleep mode. This dual-boot feature allows the chemical redox environment at a deployment location to be surveyed in real time to determine an optimum voltammetry scanning regime. Additional ongoing developments include miniaturization of analyzer electronics for incorporation into downhole deployment strategies and long-term reliability of electrodes.

\section{Downhole sampling from a submersible}

When the initial downhole strings were removed from the boreholes, several boreholes discharged (produced) fluids. This allowed a variety of samplers to be used to collect fluids near the point of discharge (e.g., major and gas-tight samplers). The first sampling effort used a winch and a pump connected to the submersible Alvin to sample the open borehole in Hole 892A. When the data logger and pressure sensor were removed, pieces of hydrate floated out of the borehole and into the water column. Attempts to deploy the sampler failed because the borehole was plugged with gas hydrates, demonstrating the difficulty of conducting a passive, in situ experiment in convergent margin with gas hydrates (Carson et al., 2003).

The Scripps wireline tool coupled with the Gieskes water sampler was used to sample fluids within the borehole in Hole 1026B (Spiess et al., 1992). However, temperature was an issue with the Gieskes water sampler. After exposure ( $15 \mathrm{~min})$ to temperatures of $64^{\circ} \mathrm{C}$ the electronics failed. Instead, fluids were collected from within the borehole using a winch, pump, and sample system deployed by the 
Alvin, similar to that used in Hole 892A (Wheat et al., 2004). An intake was placed in the borehole, and the winch was used to lower the intake to 175 meters below seafloor (mbsf). A pump mounted on the Alvin brought fluids from depth to the seafloor through a manifold of samplers that were triggered with a manipulator on the submersible. A similar system was deployed in Hole 1200C to collect fluids from the base of the borehole. Here a winch system was deployed with a spring to detect changes in resistance when extracting the sampler, thus minimizing the chance for getting the system caught on a protruding object within the borehole. This microbial sampling device minimized or eliminated contamination with seawater (K. Takai, pers. comm., 2009).

\section{Deployments and recoveries}

\section{Downhole deployment and recovery from the drillship}

The initial deployment of downhole packages occurs on the drilling vessel during installation of the CORKs (Fig. F2). Individual packages are connected on the rig floor with shackles and electrical isolators. A sinker bar is positioned at the base of the package and connected to a variety of OsmoSampler packages. These packages are connected to a sealing plug, which is connected to $0.95 \mathrm{~cm}(0.375 \mathrm{inch})$ diameter Spectra cable. These items (collectively known as the borehole instrument string) are lowered into the borehole from the rig floor using tuggers. Considering that these strings are recovered using cranes from a supporting scientific research vessel and the derrick on the drilling vessel accommodates $30 \mathrm{~m}$ high lifts, rope holds are required every $\sim 25 \mathrm{~m}$ for maneuvering the string into place on the rig floor. Yale grips are used and removed at the rig floor. Recently, loops of Spectra were hand-spliced into the main Spectra line prior to deployment to simplify the deployment and recovery processes. A video documenting the construction and deployment process of a CORK instrument string with OsmoSamplers is available at www.youtube.com/watch?v=-SNINUg6rz0/.

At this time, only downhole strings from Holes $1253 \mathrm{~A}$ and $1255 \mathrm{~A}$ have been recovered with the drillship. An attempt will be made with the JOIDES Resolution in late 2011 during Expedition 336 to recover a third string deployed during Leg 174B (Hole 395A) (Becker, Malone, et al., 1998). Recovery with the drillship is the reverse of the deployment procedure described above: first, a CORK-latching tool attaches the drill string to the CORK wellhead; a wireline tool is then sent down the inside of the drill string and latched to the top plug, releasing any latches to the CORK body; the top plug and string are retrieved using the wireline within the drill pipe; and then $25 \mathrm{~m}$ long sections are removed at the rig floor using tuggers.

\section{Submersible deployment of downhole strings}

Downhole deployments that do not use the drilling vessel but instead use a scientific submersible are more complicated (Fig. F12; see SINKER in CORK in "Supplementary material"). As before, OsmoSampler packages are shackled together with a sinker bar at the base and Spectra cable and a top seal above, similar to the deployment from the drillship. However, the sinker bar is then placed in a drop weight and held in place with a steel T-handled pin. The drop weight has containers that hold a transponder and a directional transponder (homing device) for navigation. Above the top plug is another line (polypropylene) attached to a series of floats. Polypropylene is used here because it is easy to cut underwater with a knife wielded by a submersible's manipulator. Once assembled, the entire string with flotation is lowered over the side of the support ship via cranes and then released at the surface. A transponder tracks the location of the string during descent and provides a target for the submersible.

Critical to submersible operations is the weight of the various items on the string. Including the drop weight, the overall weight must be at least $68 \mathrm{~kg}$ $(150 \mathrm{lb})$ negative so that the package sinks quickly and does not drift far from the planned drop site. Alternatively, the string can be lowered to $100 \mathrm{~m}$ above the seafloor and released with an electrical release coupled to the conductive-temperature-depth (CTD) cable. Once the drop weight is disconnected and the transponder and homing device are recovered by the submersible, the downhole string with floats should weigh 23-45 kg (50-100 lb) in seawater. The sinker bar should be at least $68 \mathrm{~kg}(150 \mathrm{lb})$ in water so that if the string is dropped by the submersible only the sinker bar will land on the seafloor and the string will remain in the water column. A weight of 23$45 \mathrm{~kg}$ is easily moved by the submersible and provides ample weight to keep the string from floating away. If the string is buoyant when detached from the drop weight, the submersible must ascend the string and release one or two of the floats. Once the string is in place on the wellhead, the string's weight should be enough to pull the string into the borehole. If the borehole is producing warm hydrothermal water, additional weight is required to overcome the hydraulic forces pushing up on the string. This situation may require the release of additional flotation. Once the string is in place, the remaining floats are released and recovered by the surface ship. Note 
that a middle sinker bar $\sim 20 \mathrm{~m}$ from the top plug is a good idea if there is a bottom seal. This middle sinker bar will pull in slack Spectra cable and help seal the top plug. The middle sinker bar should be no more than $5 \mathrm{~cm}$ (2 inch) in diameter. Keys to a successful submersible operation are having actual weights for all objects on the string, a series of floats that can be released, and simple rigging.

\section{Submersible recovery of downhole strings Original-style CORKs}

To recover original-style CORKs, the latch holding the data logger in place must be released (Figs. F2, F13). A pulling tool specially designed to connect to the CORK is manipulated by a submersible. This tool slides between the CORK body and the data logger. The tool uses the difference in hydrostatic pressure at depth relative to that at the sea surface to drive a piston, releasing the "dogs" (latch) that hold the data logger in place. The tool remains attached to the top of the logger during recovery. With the data logger released from the CORK, the string (data logger, thermistor cable, and OsmoSamplers) is recovered either by floats, rope, wireline system, or remotely operated vehicle (ROV).

Recovery of the Barbados instrument string (Leg 156; Shipley, Ogawa, Blum, et al., 1995) was attempted using a French submersible to unlatch the data logger and float the downhole string to the surface using a bag of kerosene for buoyancy. Only one CORK string was recovered (Hole 948D). The other string (Hole 949C), which contained the OsmoSampler, remains in the borehole waiting to be recovered. Safety issues related to the volume of kerosene resulted in the development of a new recovery method.

The submersible Alvin was used to attach the pulling tool to the data loggers deployed during Leg 168 (Davis, Fisher, Firth, et al., 1997; Wheat et al., 2003a). Once the data logger was released from the latch, the submersible continued to conduct other operations. After the submersible was recovered, the Scripps wireline vehicle was used to latch onto the pulling tool and pull the tool and downhole string out of the borehole (Spiess et al., 1992). However, the Scripps wireline vehicle required a number of technical personnel to operate, and the breaking strength of the fiber optic cable used to hold and manipulate the wireline vehicle placed a restriction on the amount of tension allowed. In attempting to pull out several strings, the maximum allowable tension was reached, and a weak link on the control vehicle was severed.

The weak link severed once during pull-out attempts with the Scripps wireline vehicle, leaving the pulling tool attached to the data logger, which remained in the CORK. The following year a nylon rope was used to retrieve the string. This operation included deployment of the rope with a weight at the bottom and floats on the surface. The Alvin then latched the rope to the pulling tool. Following recovery of the submersible the nylon rope was then recovered using a capstan aboard the R/V Atlantis. Unfortunately, the recovery did not include the OsmoSampler package or sinker bar. The two unrecovered OsmoSampler packages (Holes 1025C and 1026B) were likely lost because of disturbances in the open borehole that resulted in the burial of these packages. As noted above, one must be concerned about placing any sensor or sampler into open boreholes. Using a rope to pull the string out of the hole is still the method of recovery used today, except a dedicated winch system and Plasma rope are used instead of a capstan and nylon rope. This rope-winch system is preferred because the capstan was time consuming, the rope was manually spooled, and nylon stretches significantly in tension so that the deck had to be cleared until the tension was released.

Lastly, the downhole string deployed at South Chamorro Seamount (Hole 1200C) was recovered using the ROV Jason II (Woods Hole Oceanographic Institution) (Salisbury, Shinohara, Richter, et al., 2002; Wheat et al., 2008, 2010a). The Jason II brought the pulling tool to the seafloor, released the latches holding the data logger in place, attached a line from the clump weight on the Medea to the pulling tool, and then ascended. The Jason II was recovered first, followed by the logger, thermistor cable, and OsmoSampler package. Once recovered, a dummy plug was deployed in the CORK to keep it sealed. Years later in 2009 the Japanese ROV Hyper Dolphin (Japan Agency for Marine-Earth Science and Technology) conducted similar operations to recover the dummy plug and deploy new sensors and samplers within the borehole (Fig. F13).

\section{CORK-Ils and L-CORKs}

A Plasma rope connected to the top plug of the sample string can be used to recover downhole strings from CORK-IIs and L-CORKs with the aid of a submersible or ROV. Two Plasma ropes exist: one is $3000 \mathrm{~m}$ long and the other is $2000 \mathrm{~m}$ long. These ropes can access any CORK deployed to date. At the base of the Plasma rope, acting as the anchor, is a milk crate containing a $50 \mathrm{~m}$ long Spectra cable, homing device, transponder, float, and $\sim 100 \mathrm{~kg}$ of steel plates in two bundles (Fig. F14). The submersible releases one of the steel bundles and positions the milk crate near the CORK. The Spectra cable in the milk crate is attached to the Plasma rope and to a 
latch that connects to the top plug at the wellhead. Top plugs differ from each other in design, as do the tools required to recover the downhole string. The original-style CORKs require the pulling tool to remove the data logger and downhole string as noted above. Other top plugs require a hook (Hole 1253A), a 3.5 inch Otis GS tool (Holes 1026B, U1301A, and U1301B), or a 2 inch RS pulling tool (Tools International Corporation, part number 40RS1200; Holes U1362A and U1362B). Once the submersible latches into the top plug, the remaining steel plates are released, which allows the float on the milk crate to pull the Spectra cable away from possible tangling hazards (e.g., handles and instruments on the wellhead). After the submersible is recovered, the Plasma rope is retrieved with a dedicated winch. The string is then pulled aboard using a series of crane picks with Yale grips or presewn lifting handles.

\section{Deployment and recovery of seafloor systems}

Seafloor sampling and sensor systems that are attached to the wellhead and deployed by the drillship require that they fit within the radius imposed by the drillship's camera system; a submersible must be used for larger components. Most submersible operations have the samplers and tools on the submersible's basket; however, some instruments are too large and require separate elevator trips. These sampling and sensor systems are attached to the wellhead via the connectors described above. Similar operations are required to recover instruments from the wellhead.

\section{Work in progress}

As the science involving CORK platforms evolves and expands, tools and techniques for monitoring and/or experimentation continue to become more sophisticated. Here, we describe some developments poised to expand the utility of subseafloor observatories.

\section{DEBI-t (Deep Exploration Biosphere Investigative Tool)}

To date, methods developed to detect microbial life in the deep biosphere involve ex situ analysis of recovered materials from boreholes. Microbial communities hosted on the recovered materials are analyzed by extracting cells or cellular components, applying dyes to visualize cells with microscopy, or by employing other analyses (Orcutt et al., 2011). Cell visualization is a standard technique, yet requires time- and labor-intensive hands-on counting of fluo- rescent cells under a microscope. Because of problems associated with the interference of fluorescent minerals and staining, researchers often resort to physically removing cells from surfaces to stain and count them separately. This too is a laborious and inefficient process that results in the loss of cells and information about the mineralogical context that may have influenced the microbial ecology.

To meet challenges associated with detecting and quantifying microbial life within the subsurface, a novel in situ downhole logging (wireline) tool to detect microbial life in subseafloor boreholes is in development. This tool utilizes deep ultraviolet ("deep UV," or DUV) radiation to detect cells. DUV is an optical method that enables detection and imaging of single bacterial cells on natural and opaque surfaces, including assessment of bacterial density and distribution of single cells to biofilms (Bhartia et al., 2010). DUV induces and detects native fluorescence of organic components intrinsic to the cell or spore while avoiding autofluorescence interference from the substrate, enabling detection of bacteria at spatial scales ranging from tens of centimeters to micrometers (i.e., both communities of microbes and single cells). The Deep Exploration Biosphere Investigative Tool (DEBI-t) is a wireline tool that uses DUV to map the distribution and abundance of cells in a native borehole environment. The first in situ use of this tool will occur during Expedition 336 in Deep Sea Drilling Project (DSDP) Hole 395A. This technology could become widely used to detect and map remote life, becoming a "satellite imager" application for borehole environments.

\section{Oxygen sensor}

One of the limitations of present downhole sampling capabilities is the lack of dissolved oxygen measurements. Dissolved oxygen readily exchanges through PTFE coils and can be consumed in copper coils. Measurements of dissolved oxygen would provide a gauge of the rate of oxidation within basement, particularly as the hole rebounds from drilling processes that introduce surface and bottom seawater into the formation. For example, Wheat et al. (2010) documented the consumption of nitrate during the rebound period after installation of the Hole U1301A CORK, presumably from microbial processes. Furthermore, dissolved oxygen may be quantifiable in some basaltic formation fluids, possibly in basaltic basement at the sites planned for Expedition 336.

To obtain dissolved oxygen data from the borehole, an Antares oxygen sensor has been coupled to a data logger and battery package that fits within the confines of a $6 \mathrm{~cm}$ diameter pressure vessel (RBR Ltd., 
Ottawa, Canada). Given the duration of the experiment, the small diameter of the pressure vessel, and the collection of two samples per day, the primary constraint is the length of the pressure housing. Long, narrow tubes used as pressure housings are not as strong as short, larger diameter ones. Packaging for this sensor allows it to easily mate to OsmoSampler packages and minimizes vibration to the instrument. This development represents the first geochemical sensor to be deployed in a subseafloor observatory. An alternative approach for obtaining oxygen data is to develop an OsmoSampler with glass sample coils. Glass coils are used with highpressure liquid chromatography to separate compounds for subsequent detection. Such a system may include the addition of a biocide (e.g., BOSS package), but no system has yet been tested.

\section{Gas-rich fluid sampling in gas hydrates}

Plans are being devised to deploy three new CORKs in 2013 along the Cascadia Subduction Zone to assess gas compositions and fluxes (IODP Proposal 553-Full2). These CORKs will be positioned within a gas hydrate field, building upon earlier drilling, CORK installation, and sampling attempts (Westbrook, Carson, Musgrave, et al., 1994; Carson et al., 2003). On the basis of these experiences, the new CORKs are being designed to sample dissolved gases (e.g., methane and other hydrocarbon fluxes) and ions and determine pore water seepage speeds and direction well below the bottom-simulating reflector (BSR) and the hydrate stability zone. Because of complications from hydrate formation in earlier operations, the present plan is to isolate the lower section, depriving the stability zone of dissolved gases needed for hydrate formation. This opens up the possibility of sampling two horizons as well as at the seafloor on the wellhead.

Developing samplers for this environment is not trivial. Major concerns include minimizing the annular volume within the area of interest to minimize dilution of formation fluids with seawater from drilling operations. Another major concern is the disturbance of gas-rich samples when they are exposed to conditions on the ship, where the change in pressure will likely result in the loss of sample, similar to the Hole 1200C experience. Thus, a system that automatically seals the sample tubing at pressure is being developed. Such systems typically use a mechanical spring, which is a concern for a multiyear deployment in this environment. Other closing mechanisms are being investigated.

\section{Conclusions}

The methodology of fluid sampling from CORKs has evolved and expanded during the past two decades. This growth and evolution has been conducted at a measured pace because of operational and monetary constraints, which are touched upon by Becker and Davis (2005). It would require a separate paper to fully develop the intricacies of politics and funding. Nevertheless, experience and extensive planning have allowed the advancement from simple sampling systems of the initial CORKs to multilevel borehole and seafloor sampling systems used in the recent L-CORK design. These expanding capabilities have led to sample collection and sensor efforts that have progressed our understanding of subseafloor hydrogeology, crustal evolution, and the subsurface biosphere (references herein) and are poised to aid directed research projects for the next decade.

We intended this comprehensive paper to encompass all of the efforts to date and the ideas, decisions, and steps taken so that future researchers do not repeat our "mistakes." Mechanical drawings are included as supplementary material so that everyone can gain access to borehole fluids and to spur future efforts (see CORK in "Supplementary material"). Unlike most drilling operations and oceanographic expeditions, planning for a CORK takes years of effort with input from scientists, engineers, shorebased drilling engineers, ship-based operational engineers, tool pushers, drillers, and submersible operators. Such planning cannot be overlooked given the few opportunities to deploy CORKs and the lack of money to finance repeat visits to service samplers and systems. Yet, at the end of the day, all of the planning provides a unique data set that is the only means available to address significant subseafloor problems.

\section{Acknowledgments}

This work could not have been completed without the experience and help of dedicated engineers at Texas A\&M University and operational specialists employed by Transocean. Tom Pettigrew deserves the most credit for the success of CORK programs. Michael Storms and Wayne Malone were indispensable in overseeing smooth CORK operations during drilling expeditions, where plans change daily in response to hole and installation conditions. Last, but certainly not least, are Joe "Bubba" Attryde and Philip Christie, who provided creative solutions to issues that appeared to be insurmountable. We 
would also like to extend our thanks to the captains and crews of the research vessels, especially the crews of the R/V Atlantis, and to the skilled pilots of the DSRV Alvin and ROV Jason II who have helped us recover many instrument strings over the years. This short acknowledgment is not commensurate with the effort and creativity that these men and women provided to make us successful. This manuscript was improved by comments from D. Stakes and an anonymous reviewer. This work was supported by the US National Science Foundation, the Ocean Drilling Program, the Integrated Ocean Drilling Program, and the Gordon and Betty Moore Foundation. CDEBI contribution number 103.

\section{References}

Alt, J.C., 2004. Alteration of the upper oceanic crust: mineralogy, chemistry, and processes. In Elderfield, H., and Davis, E. (Eds.), Hydrogeology of the Oceanic Lithosphere: New York (Cambridge Univ. Press), 456-488.

Becker, K., and Davis, E.E., 2005. A review of CORK designs and operations during the Ocean Drilling Program. In Fisher, A.T., Urabe, T., Klaus, A., and the Expedition 301 Scientists, Proc. IODP, 301: College Station, TX (Integrated Ocean Drilling Program Management International, Inc.). doi:10.2204/iodp.proc.301.104.2005

Becker, K., Malone, M.J., et al., 1998. Proc. ODP, Init. Repts., 174B: College Station, TX (Ocean Drilling Program). doi:10.2973/odp.proc.ir.174B.1998

Bhartia, R., Salas, E.C., Hug, W.F., Reid, R.D., Lane, A.L., Edwards, K.J., and Nealson, K.H., 2010. Label-free bacterial imaging with deep-UV laser-induced native fluorescence. Appl. Environ. Microbiol., 76(21):7231-7237. doi:10.1128/AEM.00943-10

Butterfield, D.A., McDuff, R.E., Franklin, J., and Wheat, C.G., 1994. Geochemistry of hydrothermal vent fluids from Middle Valley, Juan de Fuca Ridge. In Mottl, M.J., Davis, E.E., Fisher, A.T., and Slack, J.F. (Eds.), Proc. ODP, Sci. Results, 139: College Station, TX (Ocean Drilling Program), 395-410. doi:10.2973/ odp.proc.sr.139.266.1994

Carson, B., Kastner, M., Bartlett, D., Jaeger, J., Jannasch, H., and Weinstein, Y., 2003. Implications of carbon flux from the Cascadia accretionary prism: results from long-term, in situ measurements at ODP Site 892B. Mar. Geol., 198(1-2):159-180. doi:10.1016/ S0025-3227(03)00099-9

Cath, T.Y., Childress, A.E., and Elimelech, M., 2006. Forward osmosis: principles, applications, and recent developments. J. Membr. Sci., 281(1-2):70-87. doi:10.1016/j.memsci.2006.05.048

Cowen, J.P., 2004. The microbial biosphere of sedimentburied oceanic basement. Res. Microbiol., 155(7):497506. doi:10.1016/j.resmic.2004.03.008

Cowen, J.P., Giovannoni, S.J., Kenig, F., Johnson, H.P., Butterfield, D., Rappé, M.S., Hutnak, M., and Lam, P., 2003. Fluids from aging ocean crust that support microbial life. Science, 299(5603):120-123. doi:10.1126/science. 1075653

Cruse, A.M., and Seewald, J.S., 2006. Geochemistry of lowmolecular weight hydrocarbons in hydrothermal fluids from Middle Valley, northern Juan de Fuca Ridge. Geochim. Cosmochim. Acta, 70(8):2073-2092. doi:10.1016/ j.gca.2006.01.015

Davis, E., and Petronotis, K.E., 2010. Cascadia subduction zone ACORK observatory. IODP Sci. Prosp., 328. doi:10.2204/iodp.sp.328.2010

Davis, E.E., Becker, K., Pettigrew, T., Carson, B., and MacDonald, R., 1992. CORK: a hydrologic seal and downhole observatory for deep-ocean boreholes. In Davis, E.E., Mottl, M.J., Fisher, A.T., et al., Proc. ODP, Init. Repts., 139: College Station, TX (Ocean Drilling Program), 43-53. doi:10.2973/odp.proc.ir.139.103.1992

Davis, E.E., Fisher, A.T., Firth, J.V., et al., 1997. Proc. ODP, Init. Repts., 168: College Station, TX (Ocean Drilling Program). doi:10.2973/odp.proc.ir.168.1997

Davis, E.E., Malone, M.J., and the Expedition 328 Scientists and Engineers, 2010. Cascadia subduction zone ACORK observatory. IODP Prel. Rept., 328. doi:10.2204/ iodp.pr.328.2010

Davis, E.E., Mottl, M.J., Fisher, A.T., et al., 1992. Proc. ODP, Init. Repts., 139: College Station, TX (Ocean Drilling Program). doi:10.2973/odp.proc.ir.139.1992

Edwards, K.J., Bach, W., and Klaus, A., 2010. Mid-Atlantic Ridge flank microbiology: initiation of long-term coupled microbiological, geochemical, and hydrological experimentation within the seafloor at North Pond, western flank of the Mid-Atlantic Ridge. IODP Sci. Prosp., 336. doi:10.2204/iodp.sp.336.2010

Edwards, K.J., Bach, W., and McCollom, T.M., 2005. Geomicrobiology in oceanography: microbe-mineral interactions at and below the seafloor. Trends Microbiol., 13(9):449-456. doi:10.1016/j.tim.2005.07.005

Fisher, A.T., Urabe, T., Klaus, A., and the Expedition 301 Scientists, 2005. Proc. IODP, 301: College Station, TX (Integrated Ocean Drilling Program Management International, Inc.). doi:10.2204/iodp.proc.301.2005

Fisher, A.T., Wheat, C.G., Becker, K., Davis, E.E., Jannasch, H., Schroeder, D., Dixon, R., Pettigrew, T.L., Meldrum, R., McDonald, R., Nielsen, M., Fisk, M., Cowen, J., Bach, W., and Edwards, K., 2005. Scientific and technical design and deployment of long-term subseafloor observatories for hydrogeologic and related experiments, IODP Expedition 301, eastern flank of Juan de Fuca Ridge. In Fisher, A.T., Urabe, T., Klaus, A., and the Expedition 301 Scientists, Proc. IODP, 301: College Station, TX (Integrated Ocean Drilling Program Management International, Inc.). doi:10.2204/ iodp.proc.301.103.2005

Gieskes, J.M., and Magenheim, A.J., 1992. Borehole fluid chemistry of DSDP Holes 395A and 534A results from Operation Dianaut. Geophys. Res. Lett., 19(5):513-516. doi:10.1029/91GL02769

Girguis, P.R., Robidart, J., and Wheat, G., 2008. The BOSS: a novel approach to coupling temporal changes in geochemistry and microbiology in the deep subsurface biosphere. Eos, Trans. Am. Geophys. Union, 
89(53)(Suppl.):B51F-03. (Abstract) http://

www.agu.org/meetings/fm08/waisfm08.html

Glazer, B.T., and Rouxel, O.J., 2009. Redox speciation and distribution within diverse iron-dominated microbial habitats at Loihi Seamount. Geomicrobiol. J., 268(8):606622. doi:10.1080/01490450903263392

Gray, G.T., McCutcheon, J.R., and Elimelech, M., 2006. Internal concentration polarization in forward osmosis: role of membrane orientation. Desalination, 197(1-3):18. doi:10.1016/j.desal.2006.02.003

Hulme, S., and Wheat, C.G., 2010. Fluid and chemical fluxes along a buried-basement ridge in the eastern Juan de Fuca Ridge flank. Eos, Trans. Am. Geophys. Union, 91(Fall Suppl.):U43A-0001. (Poster) http:// www.agu.org/meetings/fm10/waisfm10.html

Jannasch, H.W., Davis, E.E., Kastner, M., Morris, J.D., Pettigrew, T.L., Plant, J.N., Solomon, E.A., Villinger, H.W., and Wheat, C.G., 2003. CORK-II: long-term monitoring of fluid chemistry, fluxes, and hydrology in instrumented boreholes at the Costa Rica subduction zone. In Morris, J.D., Villinger, H.W., Klaus, A., Proc. ODP, Init. Repts., 205: College Station, TX (Ocean Drilling Program), 1-36. doi:10.2973/odp.proc.ir.205.102.2003

Jannasch, H.W., Wheat, C.G., Plant, J.N., Kastner, M., and Stakes, D.S., 2004. Continuous chemical monitoring with osmotically pumped water samplers: OsmoSampler design and applications. Limnol. Oceanogr.: Methods, 2:102-113. http://aslo.org/lomethods/free/2004/ 0102.pdf

Kastner, M., Becker, K., Davis, E.E., Fisher, A.T., Jannasch, H.W., Solomon, E.A., and Wheat, G., 2006. New insights into the hydrogeology of the oceanic crust through long-term monitoring. Oceanography, 19(4):4657. http://www.tos.org/oceanography/issues/ issue_archive/issue_pdfs/19_4/ 19.4_kastner_et_al.pdf

Kopf, A., Araki, E., and Toczko, S., 2010. NanTroSEIZE Stage 2: riserless observatory. IODP Sci. Prosp., 332. doi:10.2204/iodp.sp.332.2010

Lapham, L.L., Chanton, J.P., Martens, C.S., Higley, P.D., Jannasch, H.W., and Woolsey, J.R., 2008. Measuring temporal variability in pore-fluid chemistry to assess gas hydrate stability: development of a continuous porefluid array. Environ. Sci. Technol., 42(19):7368-7373. doi:10.1021/es801195m

Luther, G.W., III, Glazer, B.T., Ma, S., Trouwborst, R.E., Moore, T.S., Metzger, E., Kraiya, C., Waite, T.J., Druschel, G., Sundby, B., Taillefert, M., Nuzzio, D.B., Shank, T.M., Lewis, B.L., and Brendel, P.J., 2008. Use of voltammetric solid-state (micro)electrodes for studying biogeochemical processes: laboratory measurements to real time measurements with an in situ electrochemical analyzer (ISEA). Mar. Chem., 108(3-4):221-235. doi:10.1016/ j.marchem.2007.03.002

Magenheim, A.J., Bayhurst, G., Alt, J.C., and Gieskes, J.M., 1992. ODP Leg 137, borehole fluid chemistry in Hole 504B. Geophys. Res. Lett., 19(5):521-524. doi:10.1029/ 91GL02948

Magenheim, A.J., Spivack, A.J., Alt, J.C., Bayhurst, G., Chan, L.-H., Zuleger, E., and Gieskes, J.M., 1995. Bore- hole fluid chemistry in Hole 504B, Leg 137: formation water or in-situ reaction? In Erzinger, J., Becker, K., Dick, H.J.B., and Stokking, L.B. (Eds.), Proc. ODP, Sci. Results, 137/140: College Station, TX (Ocean Drilling Program), 141-152. doi:10.2973/odp.proc.sr.137140.024.1995

Mikada, H., Becker, K., Moore, J.C., Klaus, A., et al., 2002. Proc. ODP, Init. Repts., 196: College Station, TX (Ocean Drilling Program). doi:10.2973/odp.proc.ir.196.2002

Morris, J.D., Villinger, H.W., Klaus, A., et al., 2003. Proc. ODP, Init. Repts., 205: College Station, TX (Ocean Drilling Program). doi:10.2973/odp.proc.ir.205.2003

Mottl, M.J., and Gieskes, J.M., 1990. Chemistry of waters sampled from oceanic basement boreholes, 1979-1988. J. Geophys. Res., [Solid Earth], 95(B6):9327-9342. doi:10.1029/JB095iB06p09327

Orcutt, B., Wheat, C.G., and Edwards, K.J., 2010. Subseafloor ocean crust microbial observatories: development of FLOCS (Flow-Through Osmo Colonization System) and evaluation of borehole construction materials. Geomicrobiol. J., 27(2):143-157. doi:10.1080/ 01490450903456772

Orcutt, B.N., Bach, W., Becker, K., Fisher, A.T., Hentscher, M., Toner, B.M., Wheat, C.G., and Edwards, K.J., 2011. Colonization of subsurface microbial observatories deployed in young ocean crust. ISME J., 5(4):692-703. doi:10.1038/ismej.2010.157

Nakagawa, S., Inagaki, F., Suzuki, Y., Steinsbu, B.O., Lever, M.A., Takai, K., Engelen, B., Sako, Y., Wheat, C.G., Horikoshi, K., and Integrated Ocean Drilling Program Expedition 301 Scientists, 2006. Microbial community in black rust exposed to hot ridge-flank crustal fluids. Appl. Environ. Microbiol., 72(10):6789-6799. doi:10.1128/ AEM.01238-06

Parsons, B., and Sclater, J.G., 1977. An analysis of the variation of ocean floor bathymetry and heat flow with age. J. Geophys. Res., [Solid Earth], 82:803-827. doi:10.1029/ JB082i005p00803

Saffer, D., McNeill, L., Byrne, T., Araki, E., Toczko, S., Eguchi, N., Takahashi, K., and the Expedition 319 Scientists, 2010. Proc. IODP, 319: Tokyo (Integrated Ocean Drilling Program management International, Inc.). doi:10.2204/iodp.proc.319.2010

Salisbury, M.H., Shinohara, M., Richter, C., et al., 2002. Proc. ODP, Init. Repts., 195: College Station, TX (Ocean Drilling Program). doi:10.2973/odp.proc.ir.195.2002

Seyfried, W.E., Jr., and Bischoff, J.L., 1979. Low temperature basalt alteration by sea water: an experimental study at $70^{\circ} \mathrm{C}$ and $150^{\circ} \mathrm{C}$. Geochim. Cosmochim. Acta, 43(12):1937-1947. doi:10.1016/0016-7037(79)90006-1

Shipley, T.H., Ogawa, Y., Blum, P., et al., 1995. Proc. ODP, Init. Repts., 156: College Station, TX (Ocean Drilling Program). doi:10.2973/odp.proc.ir.156.1995

Solomon, E.A., Kastner, M., Wheat, C.G., Jannasch, H., Robertson, G., Davis, E.E., and Morris, J.D., 2009. Longterm hydrogeochemical records in the oceanic basement and forearc prism at the Costa Rica subduction zone. Earth Planet. Sci. Lett., 282(1-4):240-251. doi:10.1016/j.epsl.2009.03.022 
Spiess, F.N., Boegeman, D.E., and Lowenstein, C., 1992. First ocean-research-ship-supported fly-in re-entry to a deep ocean drill hole. Mar. Technol. Soc. J., 26(3):3-10.

Steinsbu, B.O., Thorseth, I.H., Nakagawa, S., Inagaki, F., Lever, M.A., Engelen, B., Øvreås, L., and Pedersen, R.B., 2010. Archaeoglobus sulfaticallidus sp. nov., a thermophilic and facultatively lithoautotrophic sulfate-reducer isolated from black rust exposed to hot ridge flank crustal fluids. Int. J. Syst. Evol. Microbiol., 60(12):27452752. doi:10.1099/ijs.0.016105-0

Theeuwes, F., and Yum, S.I., 1976. Principles of the design and operation of generic osmotic pumps for the delivery of semisolid or liquid drug formulations. Ann. Biomed. Eng., 4(4):343-353. doi:10.1007/BF02584524

Wang, K.Y., Ong, R.C., and Chung, T.-S., 2010. Doubleskinned forward osmosis membranes for reducing internal concentration polarization within the porous sublayer. Ind. Eng. Chem. Res., 49(10):4824-4831. doi:10.1021/ie901592d

Westbrook, G.K., Carson, B., Musgrave, R.J., et al., 1994. Proc. ODP, Init. Repts., 146 (Pt. 1): College Station, TX (Ocean Drilling Program). doi:10.2973/ odp.proc.ir.146-1.1994

Wheat, C.G., Fryer, P., Fisher, A.T., Hulme, S., Jannasch, H., Mottl, M.J., and Becker, K., 2008. Borehole observations of fluid flow from South Chamorro Seamount, an active serpentinite mud volcano in the Mariana forearc. Earth Planet. Sci. Lett., 267(3-4):401-409. doi:10.1016/ j.epsl.2007.11.057

Wheat, C.G., Fryer, P., Takai, K., and Hulme, S., 2010a. Spotlight 9: South Chamorro Seamount, $13^{\circ} 7.00^{\prime} \mathrm{N}$, $146^{\circ} 00.00^{\prime}$ E. Oceanography, 23(1):174-175. http:// www.tos.org/oceanography/issues/issue_archive/ issue_pdfs/23_1/23-1_wheat.pdf

Wheat, C.G., Jannasch, H.W., Fisher, A.T., Becker, K., Sharkey, J., and Hulme, S., 2010b. Subseafloor seawaterbasalt-microbe reactions: continuous sampling of borehole fluids in a ridge flank environment. Geochem., Geo- phys., Geosyst., 11(7):Q07011. doi:10.1029/ 2010GC003057

Wheat, C.G., Jannasch, H.W., Kastner, M., Plant, J.N., and DeCarlo, E.H., 2003a. Seawater transport and reaction in upper oceanic basaltic basement: chemical data from continuous monitoring of sealed boreholes in a ridge flank environment. Earth Planet. Sci. Lett., 216(4):549564. doi:10.1016/S0012-821X(03)00549-1

Wheat, C.G., Jannasch, H.W., Kastner, M., Plant, J.N., DeCarlo, E.H., and Lebon, G., 2004. Venting formation fluids from deep-sea boreholes in a ridge flank setting: ODP Sites 1025 and 1026. Geochem., Geophys., Geosyst., 5(8):Q08007-Q08018. doi:10.1029/2004GC000710

Wheat, C.G., Jannasch, H.W., Plant, J.N., Moyer, C.L., Sansone, F.J., and McMurtry, G.M., 2000. Continuous sampling of hydrothermal fluids from Loihi Seamount after the 1996 event. J. Geophys. Res., [Solid Earth], 105(B8):19353-19367. doi:10.1029/2000JB900088

Wheat, C.G., McManus, J., Mottl, M.J., and Giambalvo, E., 2003b. Oceanic phosphorus imbalance: magnitude of the mid-ocean ridge flank hydrothermal sink. Geophys. Res. Lett., 30(17):1895-1898. doi:10.1029/ 2003GL017318

Wheat, C.G., and Mottl, M.J., 2004. Geochemical fluxes through mid-ocean ridge flanks. In Davis, E.E., and Elderfield, H. (Eds.), Hydrogeology of the Oceanic Lithosphere: Cambridge (Cambridge Univ. Press), 627-658.

Wommack, K.E., Williamson, S.J., Sundbergh, A., Helton, R.R., Glazer, B.T., Portune, K., and Cary, S.C., 2004. An instrument for collecting discrete large-volume water samples suitable for ecological studies of microorganisms. Deep-Sea Res., Part I, 51(11):1781-1792. doi:10.1016/S0967-0637(04)00113-X

Initial receipt: 18 November 2010

Acceptance: 15 March 2011

Publication: 5 September 2011

MS 327-109 
Figure F1. Map showing locations of CORK deployments. CORKs will be deployed in 25 boreholes by the end of 2011 (Table T1). These observatories are located in regions where fluid flows through the oceanic crust. JdF = eastern flank of Juan de Fuca Ridge (Leg 168 and Expeditions 301 and 327), MV = Middle Valley (Leg 139), Van and Or = Cascadia margin (Leg 146 and Expedition 328), CR = Costa Rica (Leg 205), Bar = Barbados Ridge (Leg 156), NP = North Pond (Leg 174B and Expedition 336), Nan = Nankai Trough (Leg 196 and Expeditions 319 and 332), SCh = South Chamorro Seamount (Leg 195).

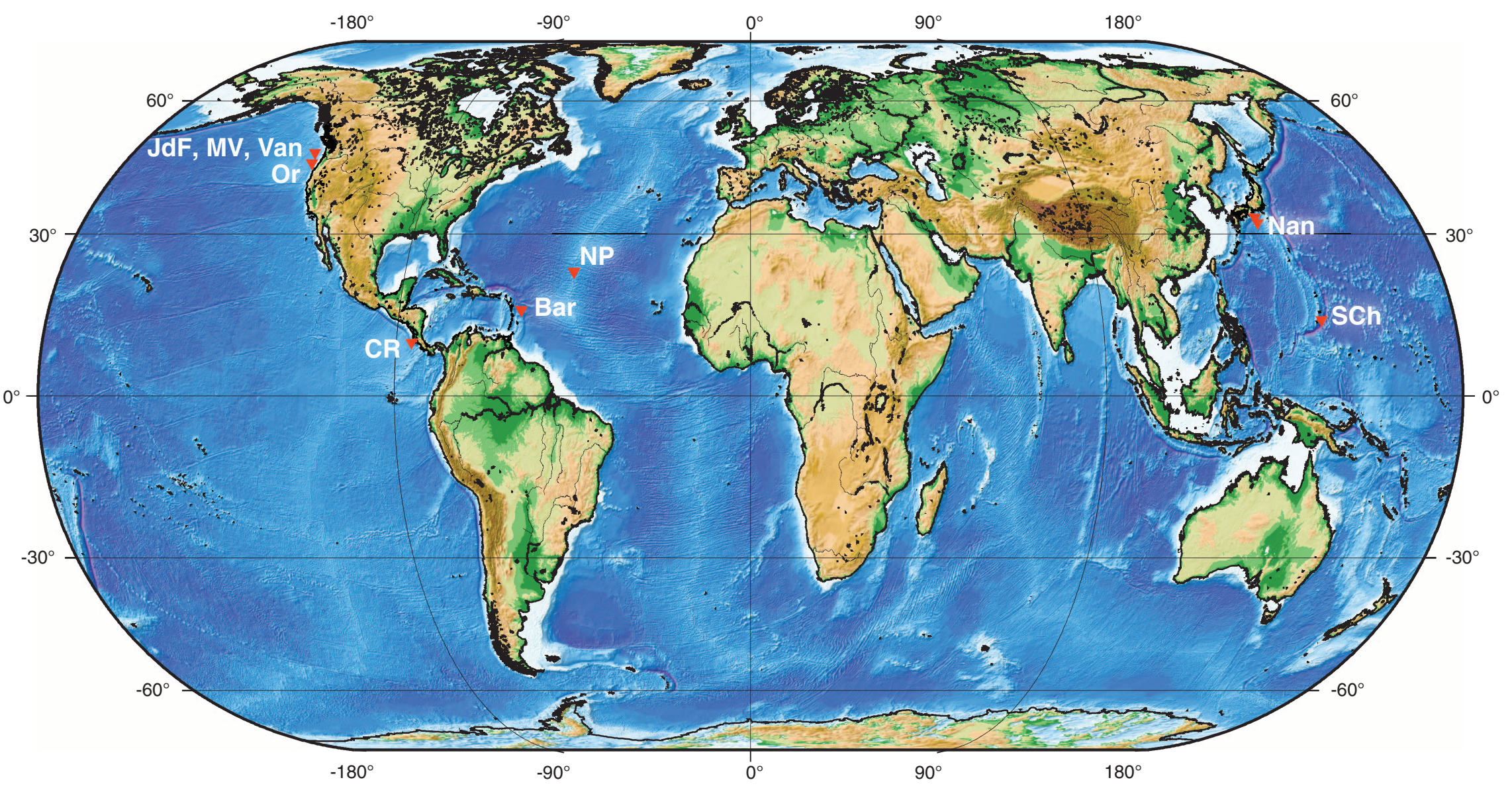


Figure F2. Schematic of original-style CORK, highlighting fluid-sampling port, valve, and CORK plug, which is typically a data logger that monitors pressure and temperature within the formation. Fluids are obtained through a modified Aeroquip fitting (see HANDLE in CORK in "Supplementary material"). The remotely operated vehicle (ROV) platform is patterned with holes large enough to sometimes lose instruments through. Inset: Photograph of OsmoSampler deployment during Leg 168. Pictured are Earl Davis, Keir Becker, Geoff Wheat, and Bill Rhinehart (Photo credit: Roy Davis). Several OsmoSampler packages are combined, sometimes exceeding $30 \mathrm{~m}$ in length (see OSMO in CORK in "Supplementary material"). For video highlights of a downhole instrument string deployment during Expedition 327, see www.youtube.com/watch?v=SNINUg6rz0/.

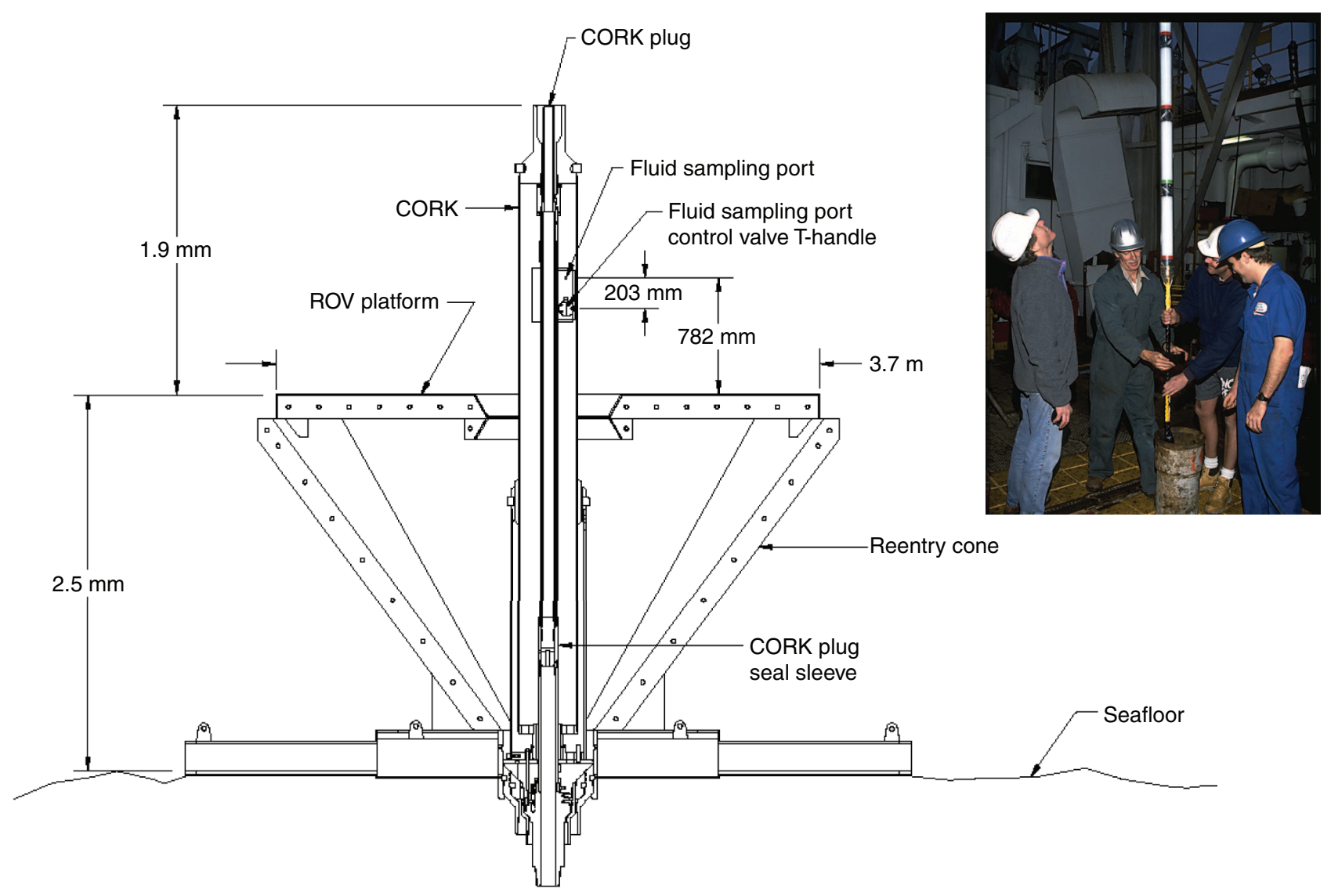


Figure F3. Schematic of L-CORK. The L-CORK is the same as the CORK-II, except a $10 \mathrm{~cm}$ ball valve is included on the wellhead (modified from Fisher, Wheat, et al.). These CORKs broaden the scope of possible sampling opportunities with capabilities for seafloor and subseafloor borehole sampling. Not all wellheads are the same. For example, the wellhead in Hole U1301B was extended. Wellheads with ball valves deployed during Expedition 327 have longer sampling bays, and the wellhead sampling bays deployed during Expedition 336 will be even longer. Photographs highlight various components shown in the schematic.

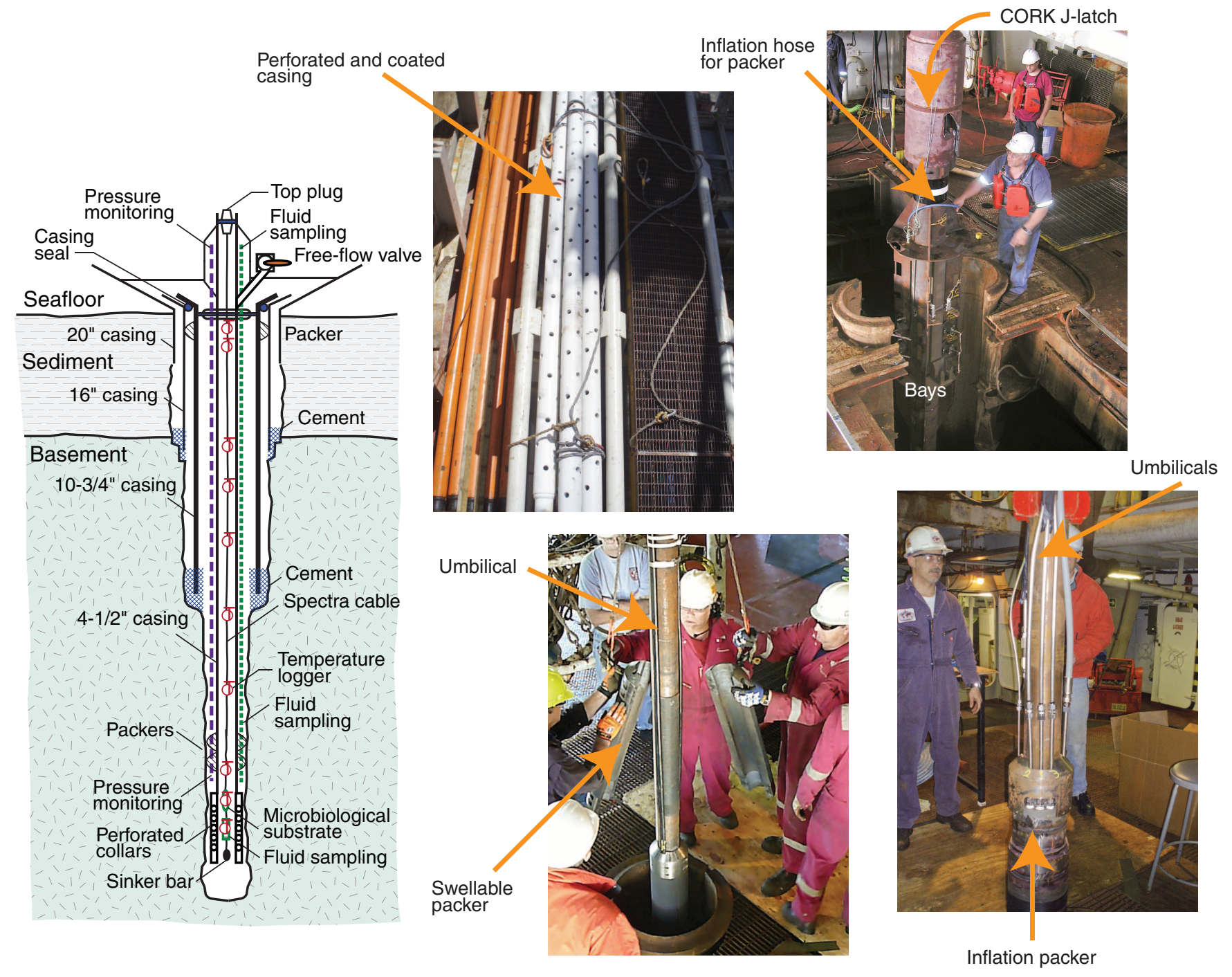


Figure F4. Illustrations and photographs of wellhead OsmoSamplers deployed on CORK-IIs during Expedition 301. (A) OsmoSamplers are mounted on (B) plates with T-handles. The plates are held in place by a submersible and then are locked in position using guides at the base and top. Once the sampler is latched in place by turning the T-handle $90^{\circ}$ and the appropriate valves are opened, fluids are obtained through (C) titanium nipples. Given a system that is overpressured relative to hydrostatic, borehole fluids should flow from the nipples to caps with O-ring seals into tubing leading to samplers. If the system is underpressured, a pump (osmotic or mechanical) is required to obtain borehole fluids. The design allows for return flow down the borehole, resulting in a closed system. D. Three samplers being prepared for deployment on the rig floor. E. An OsmoSampler and pressure gauge/discrete fluid sampler attached to the wellhead using an ROV. See GUIDE in CORK in "Supplementary material" for machine drawings of plate, PEEK couplers, and T-handle to access fluids from the wellheads deployed during Expedition 301.

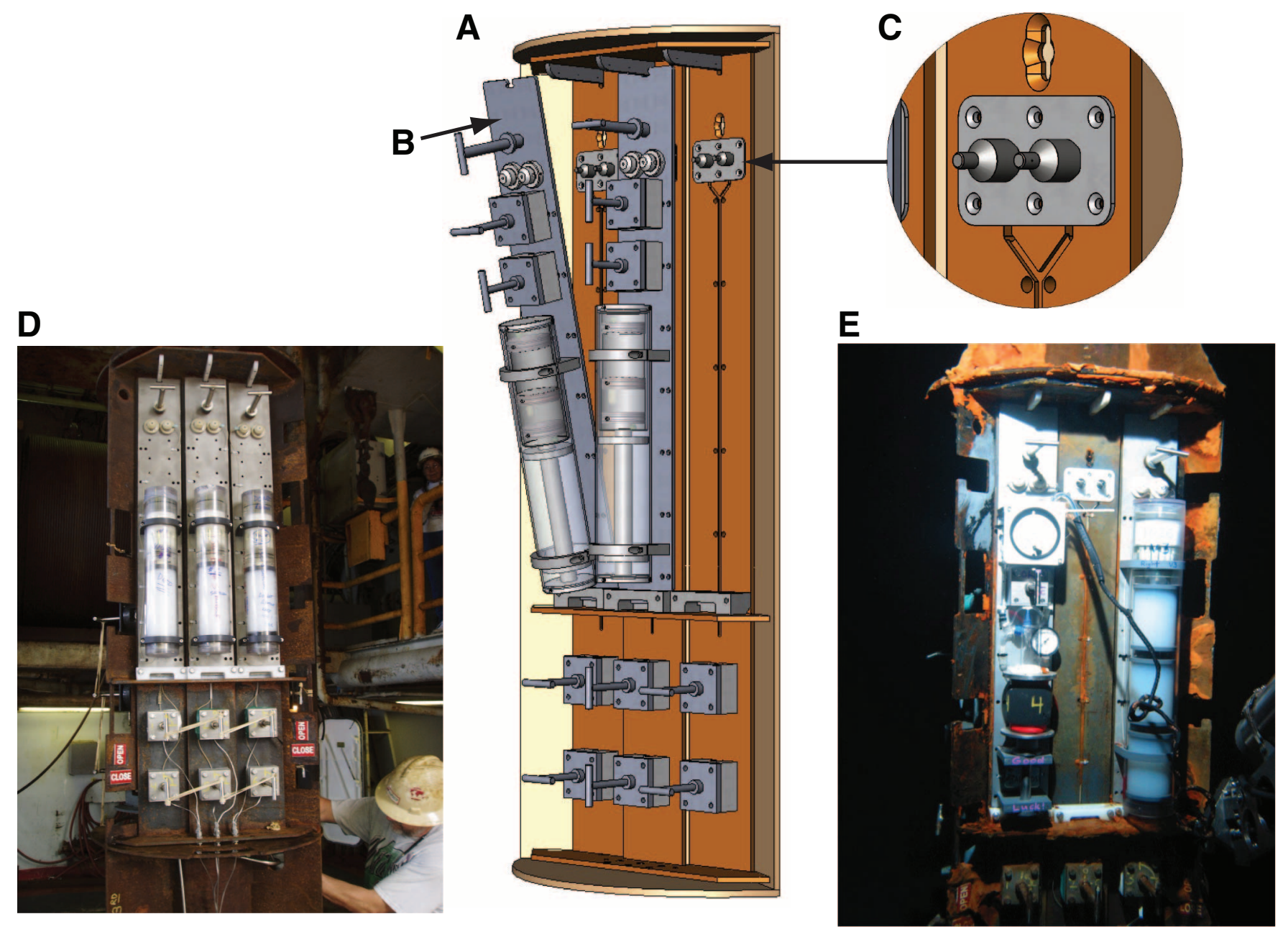


Figure F5. A. Photograph of the upper portion of geochemical bay on CORKs deployed during Expedition 327 (and planned for deployment during Expedition 336). B, C. Illustrations showing sampler components. Fluids flow up the umbilical past a (2) ball valve that is manipulated with a $(4,5)$ T-handle with a mechanical stop to a (3) PEEK tube. A sampler connects to this (3) PEEK tubing using a (7) handle with (6) two O-rings that is guided in place by an (1) ultrahigh-molecular weight base that also provides a locking mechanism for the handle. See HANDLE327 in CORK in "Supplementary material" for machine drawings of sample handles to access fluids from wellheads deployed during Expeditions 327 and 336.
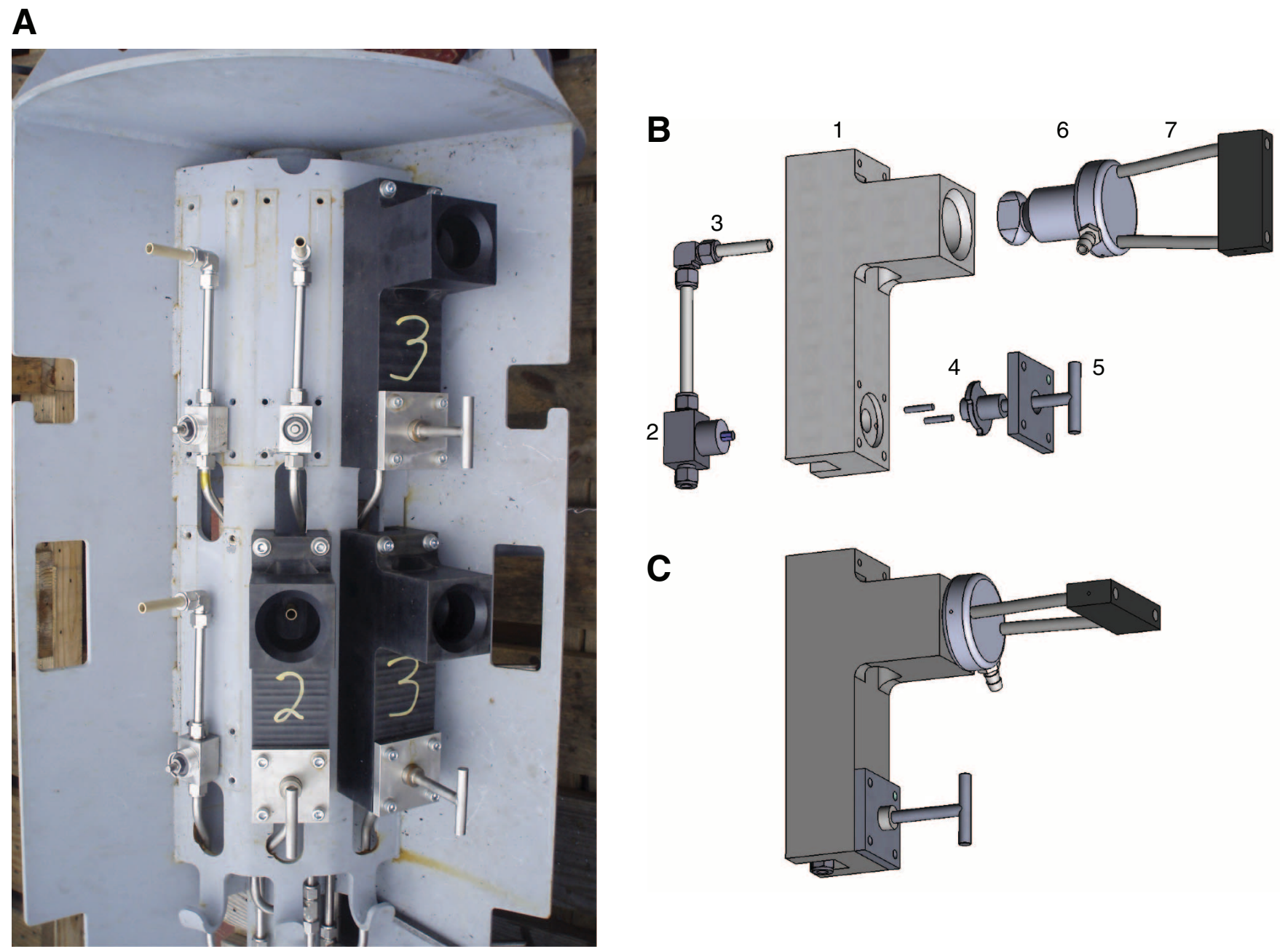
Figure F6. Photograph and illustration of "genius plug" deployed in Hole C0010A during Expedition 332. Plug includes pressure and temperature measurements, a standard OsmoSampler with two 2ML1 Alzet membranes, and a microbial colonization experiment (FLOCS; Orcutt et al., 2010), which includes some local material in the chambers that was attached to two pumps, each with two 2ML1 Alzet membranes. The OsmoSampler and FLOCS were designed to fit a diameter of $10.8 \mathrm{~cm}$ and a length of $20.2 \mathrm{~cm}$.

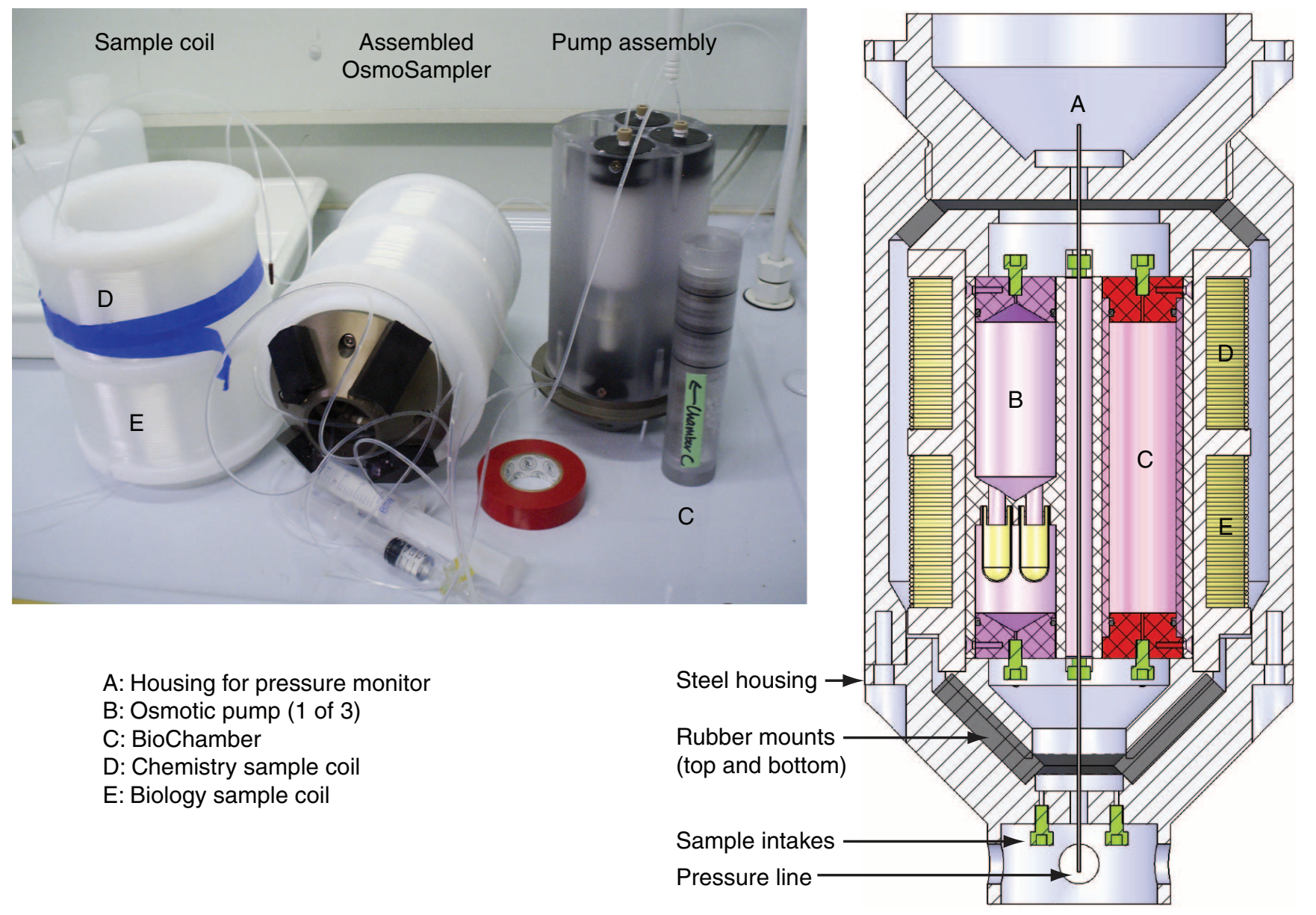


Figure F7. Illustration of forward- and reverse-osmosis systems where water is driven across a semipermeable membrane. Forward osmosis uses the osmotic gradient $(\Delta \pi)$ to counteract hydrostatic pressure $(\Delta P)$. Reverse osmosis uses a hydraulic piston to create a hydrostatic pressure in excess of the osmotic gradient and "filter" the salt. Typical downhole OsmoSamplers include at least one pump and multiple sample coils. Alzet membranes are white.

Forward osmosis (OsmoSampler)
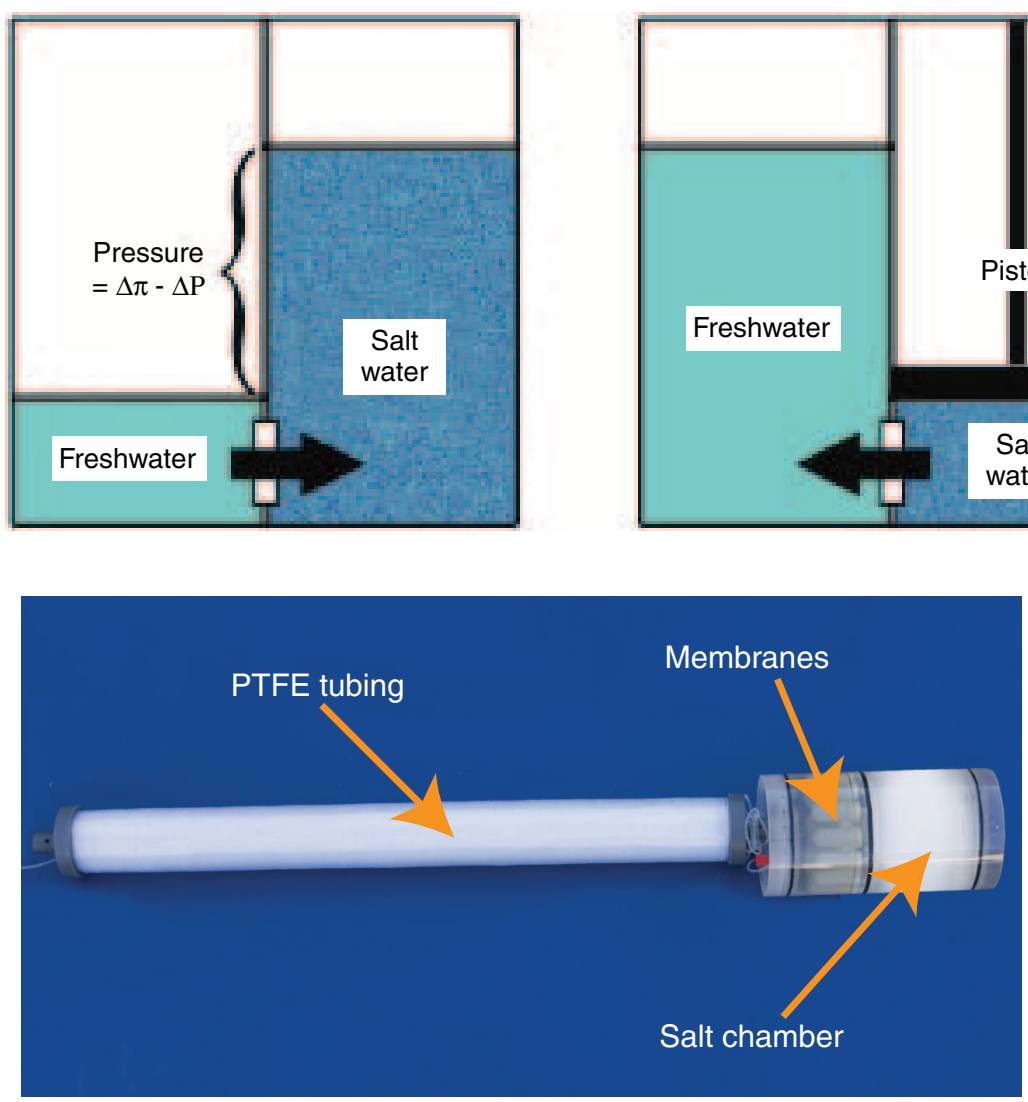

Reverse osmosis (desalinization)

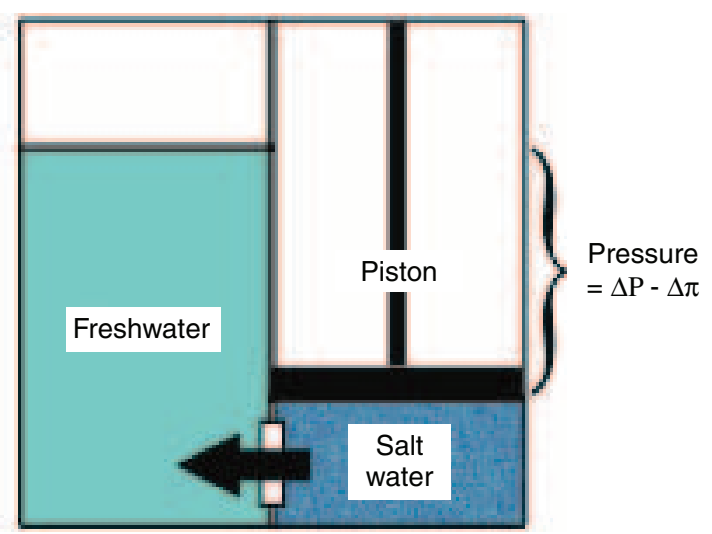

Salt chamber 
Figure F8. Photograph of typical plugs, seats, and OsmoSampler parts. Internal O-ring seals on the plugs are designed to seal on the gravity seats, allowing different hydrologic zones to be separated. Plug outer diameter and seat inner diameter decrease with depth, allowing multiple horizons to be sampled in a single borehole. OsmoSampler parts shown are PVC couplers that attach to clear protective tubing within which pumps and coils are protected. Ends are stainless steel connected to a $1.27 \mathrm{~cm}$ inner diameter stainless steel rod and galvanized $1.27 \mathrm{~cm}$ shackles (isolated with plastic).

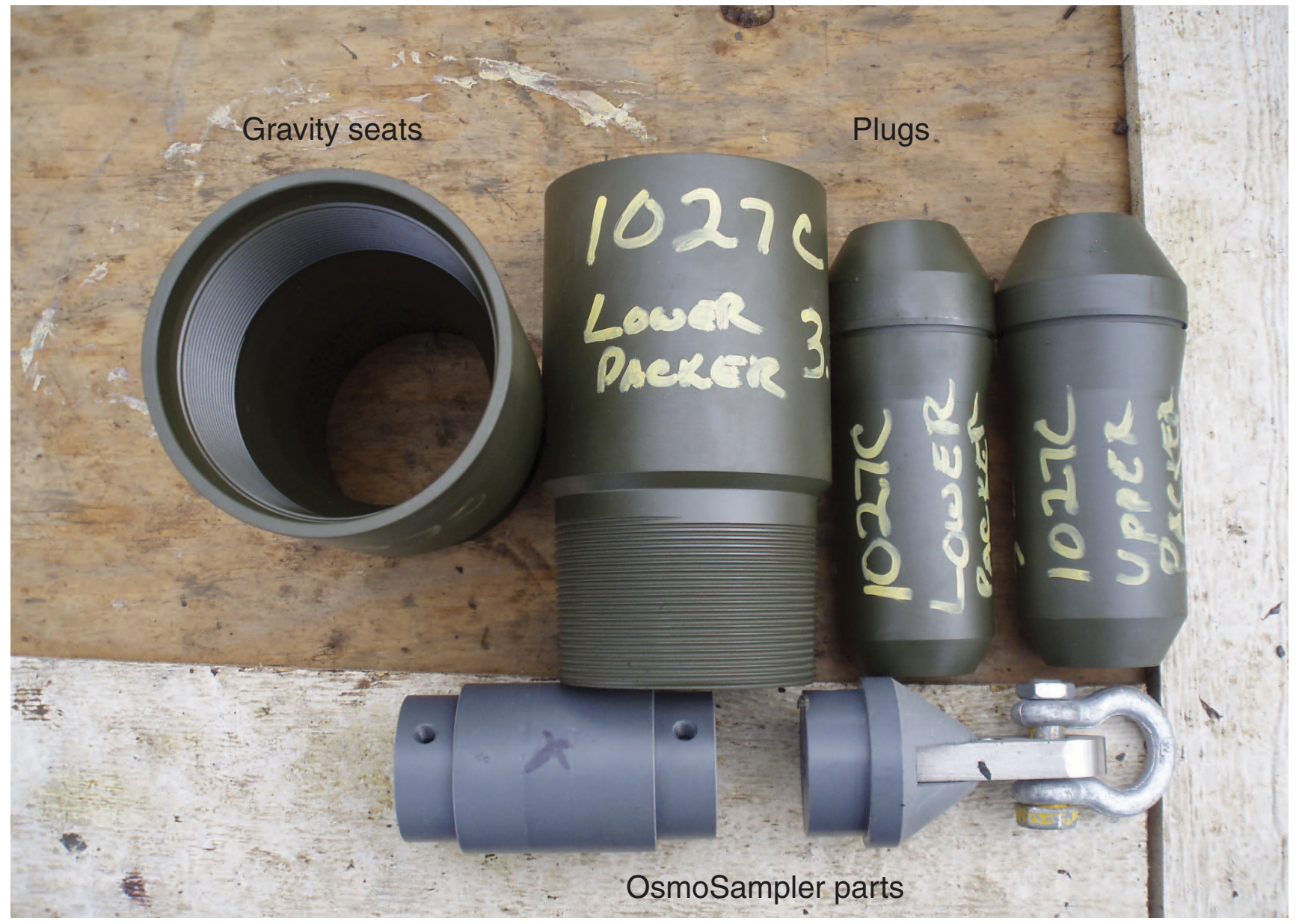


Figure F9. Photographs of fluid sampling from original-style CORK. A male Aeroquip connector protrudes from the steel cut-out. A ball valve is manipulated with the handle below the connector. The positioning of the connector near the steel bulkhead makes it difficult for submersibles to attach the female Aeroquip connector (2009; Hole 1200C) (see HANDLE in CORK in "Supplementary material"). Tubing was attached to the Aeroquip fitting and to a sample manifold. Because this formation is permeable and overpressured, borehole fluids vented through the manifold when the valve was opened. The white "smoke" is brucite that forms when this high-pH fluid mixes with seawater rich in magnesium.
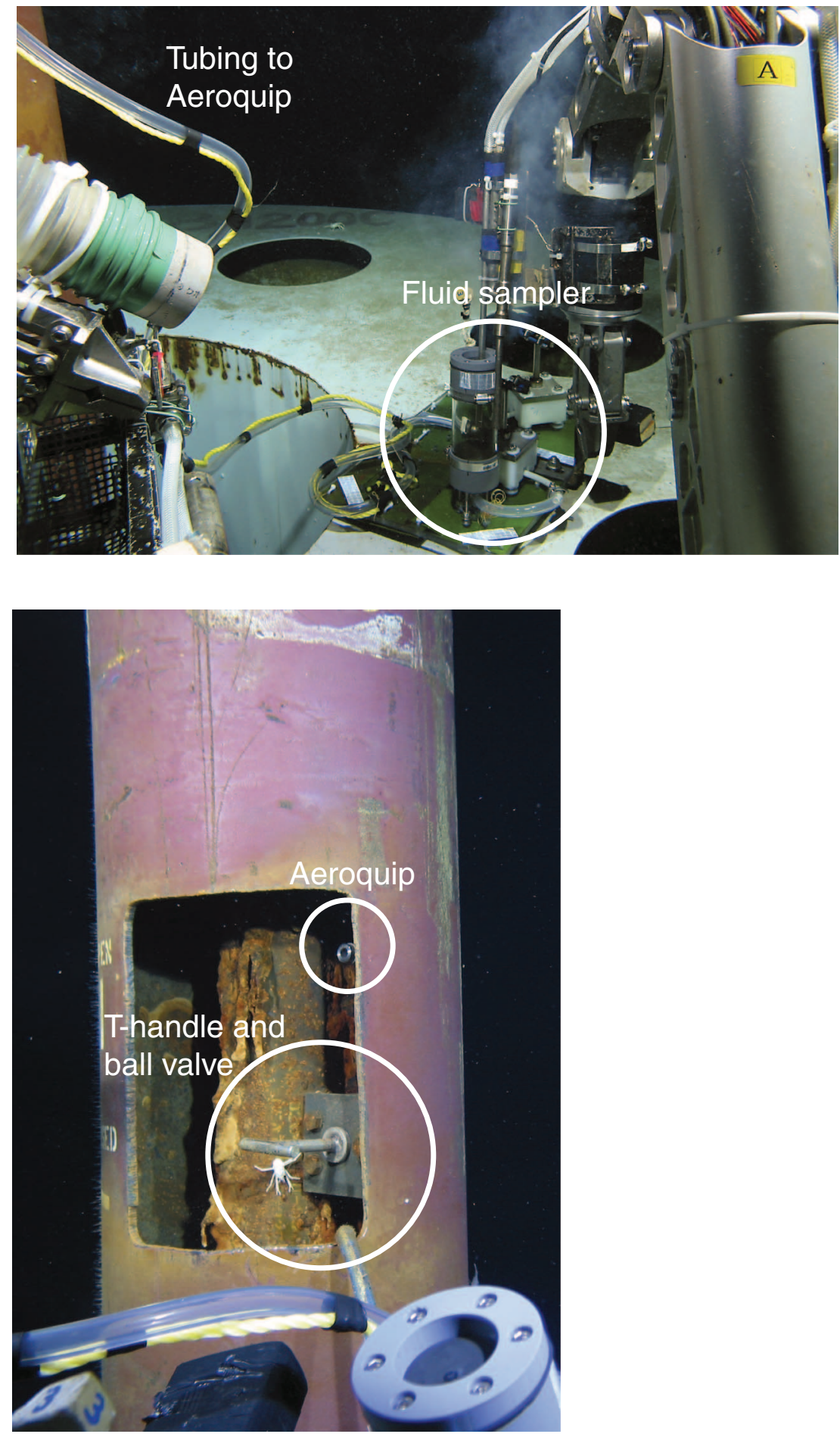
Figure F10. Photographs of female Aeroquip with elbow (see HANDLE in CORK in "Supplementary material"). Shown is a $1.27 \mathrm{~cm}(0.5 \mathrm{inch})$ stainless steel elbow; other sizes and fittings can be used and attached to a variety of sampling tools.

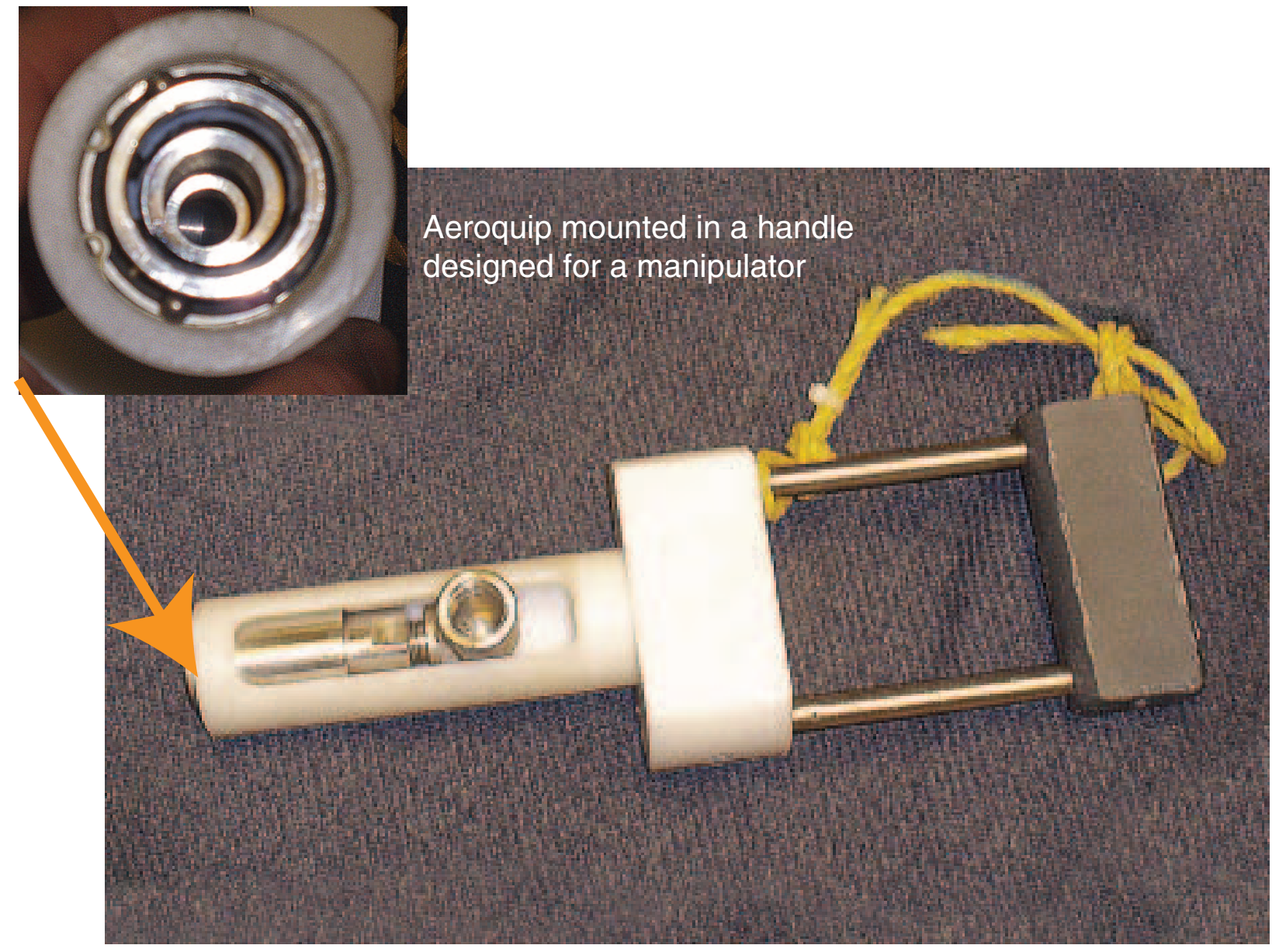


Figure F11. Photographs of samplers. A. BioColumn deployed on Hole 1026B. The BioColumn was designed for physical, geochemical, and microbial experiments. B. Large-volume fluid sampler deployed on Hole 1026B. This self-contained system has a pump that is powered with deep-sea batteries. C. GeoMICROBE sled being deployed. This sled contains pumps, thermal and chemical sensors, and samplers to collect and analyze borehole fluids pumped from the formation through an umbilical, where they are sampled at the seafloor.

A

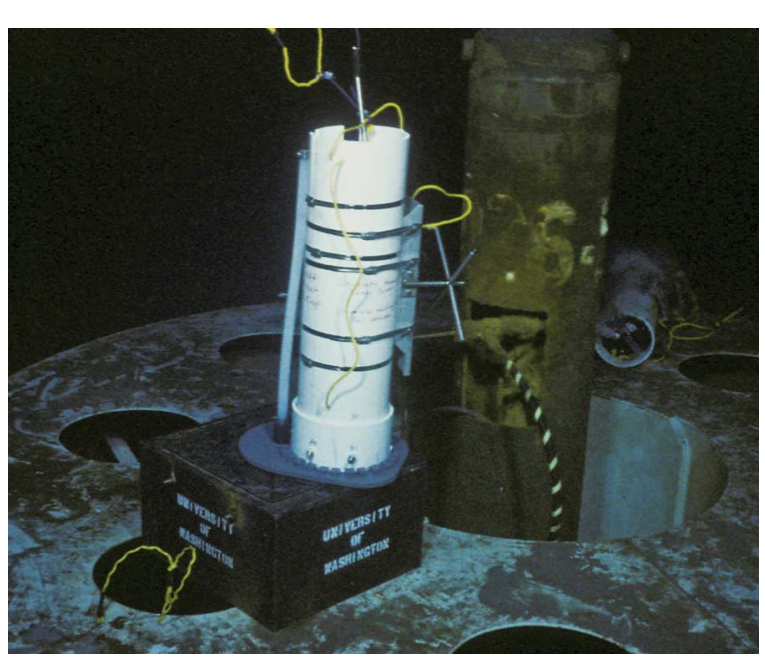

\section{C}

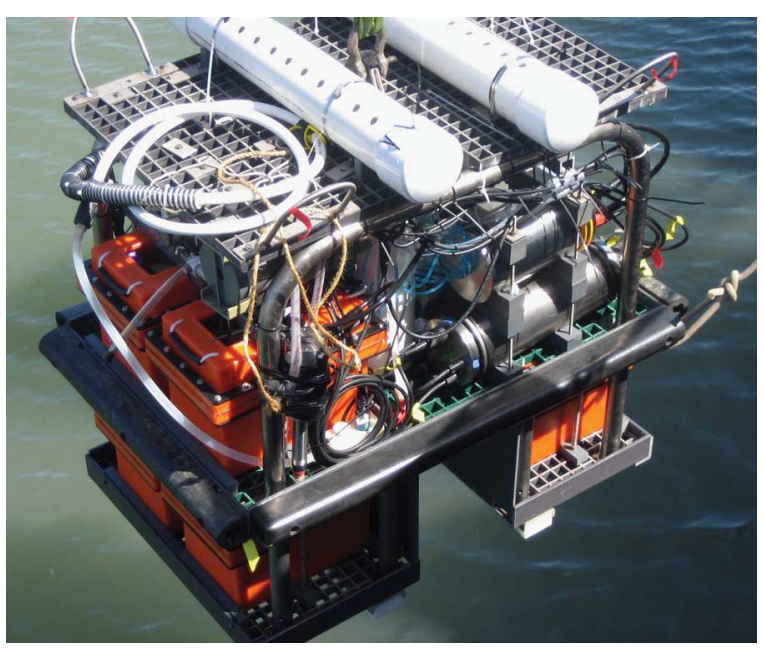

B

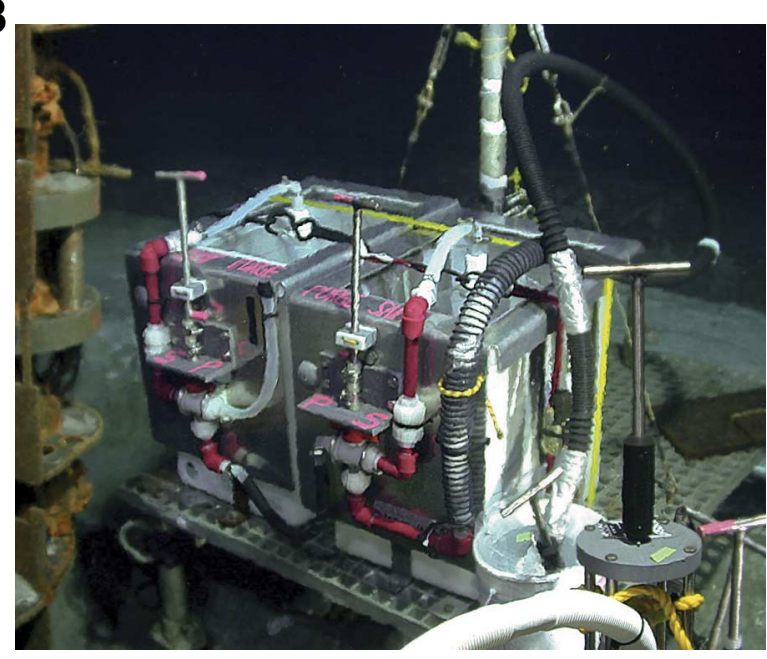


Figure F12. Diagram of a borehole instrument string deployed in Hole 1253A (4376 meters below sea level). The string is $-206 \mathrm{lb}$ when released from the ship. At the seafloor the drop weight (see SINKER in CORK in "Supplementary material") is removed, and the string is $-56 \mathrm{lb}$. If the string needs to be heavier, floats can be removed from the top of the string. Once the string is safely placed in the wellhead, the floats are released and the string descends. This example lacks a transponder and directional transponder (homing device) on the drop weight. These instruments add more weight to the system, help locate the string on the seafloor, and are recovered once the string is located. In later deployments the lead wire is replaced with a middle sinker bar $(-50$ $\mathrm{lb}$ in seawater), requiring an additional float.

Hole 1253A deployment in 2009

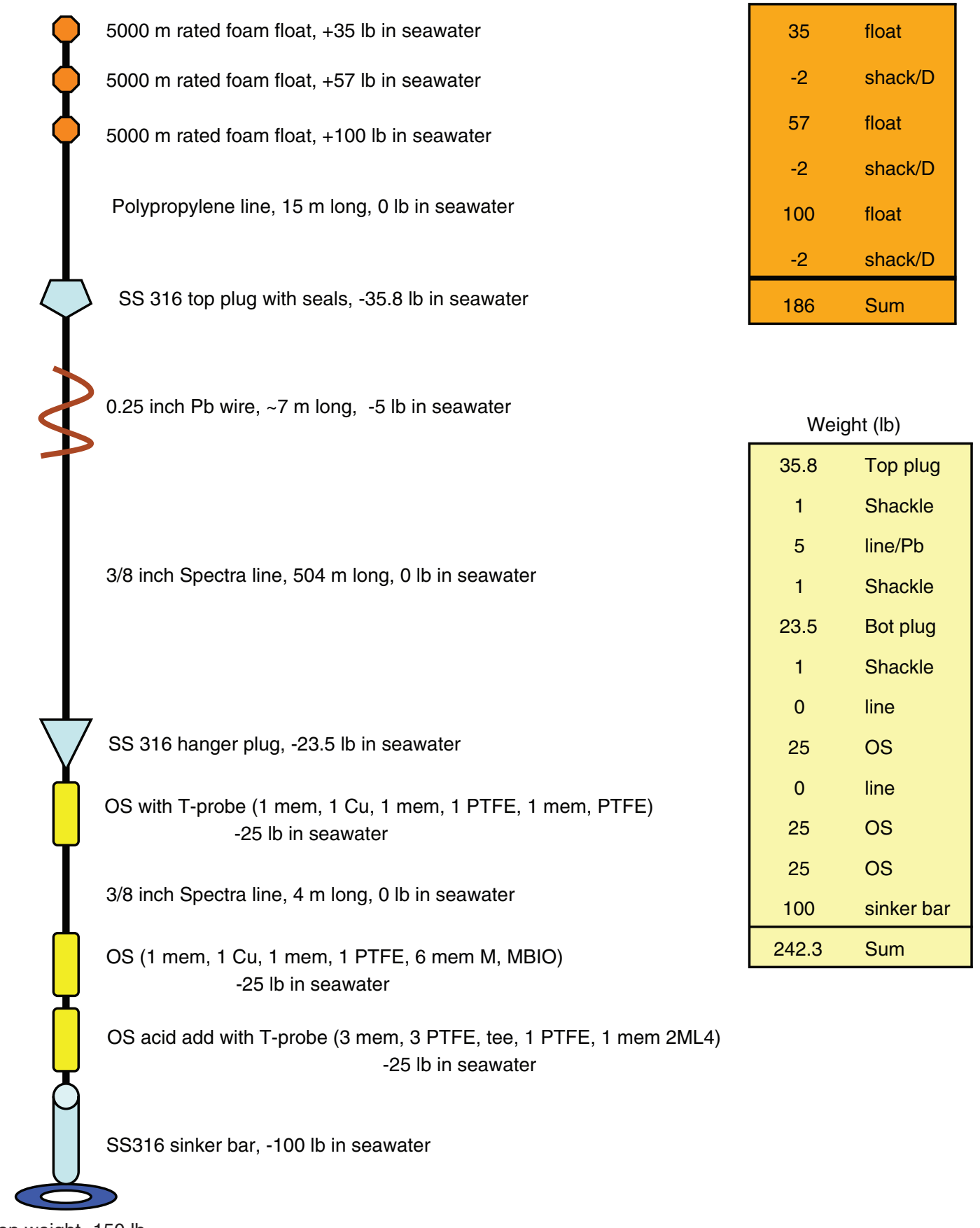

Drop weight -150 lb 
Figure F13. Photographs of pulling tool before and after deployment. A pulling tool is required to remove the logger in an original-style CORK. One was removed from Hole 1200C in 2009 using the ROV Hyper Dolphin. Once the pulling tool was in place, the valve was activated, releasing the logger. (In this case the logger was actually a steel tube inserted to seal the hole.) A line was attached to the pulling tool from the bottom of the ROV to pull the logger out of the hole. The ROV was recovered, followed by the pulling tool and logger.
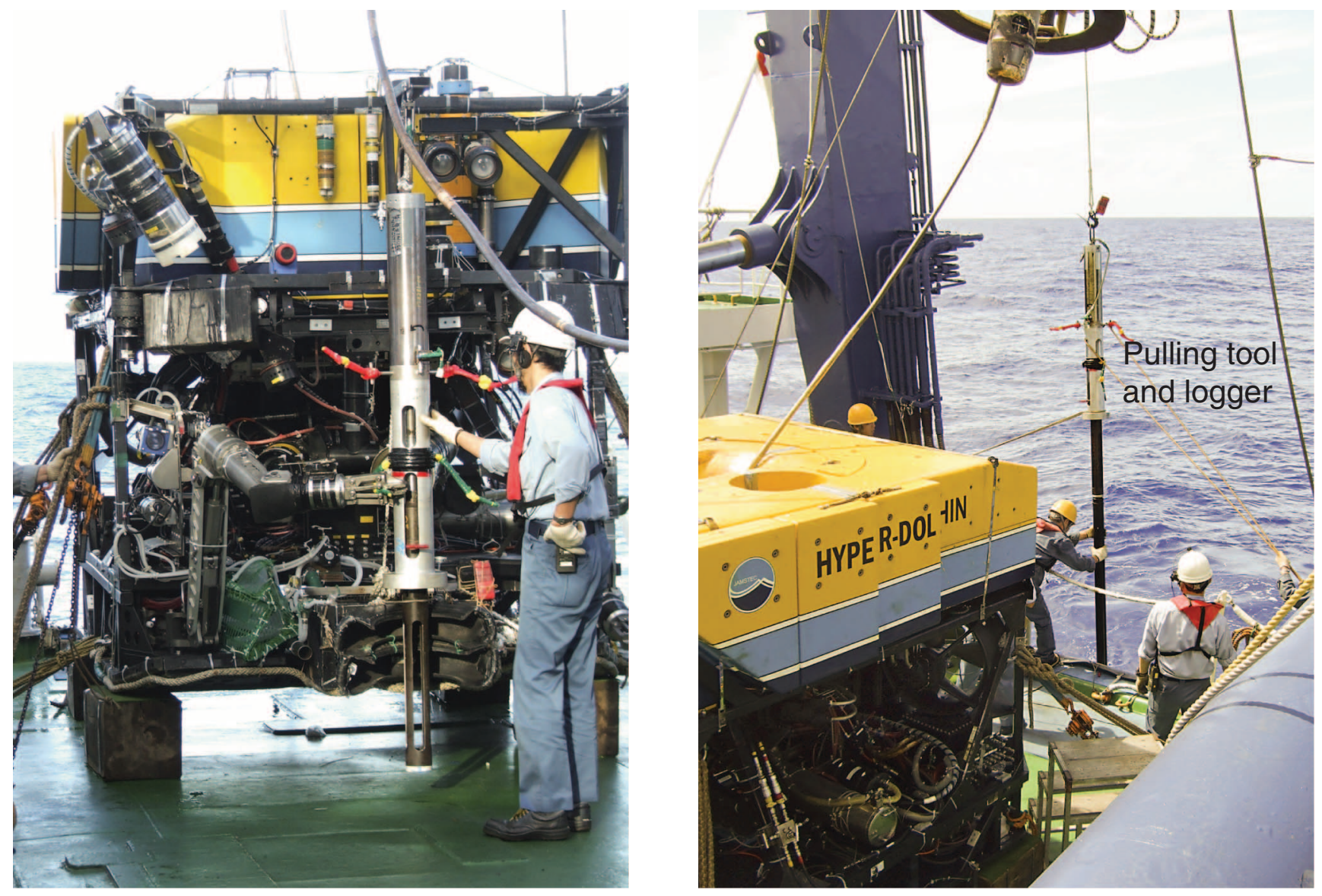
Figure F14. The seafloor portion of the recovery system, which is attached to the end of Plasma rope. Two drop weights are used. One is released before the system is moved to the wellhead. The homing device and transponder are removed and the latch is positioned before the second weight is released. A float is attached to the orange D ring to make sure the lines do not foul the wellhead during recovery.

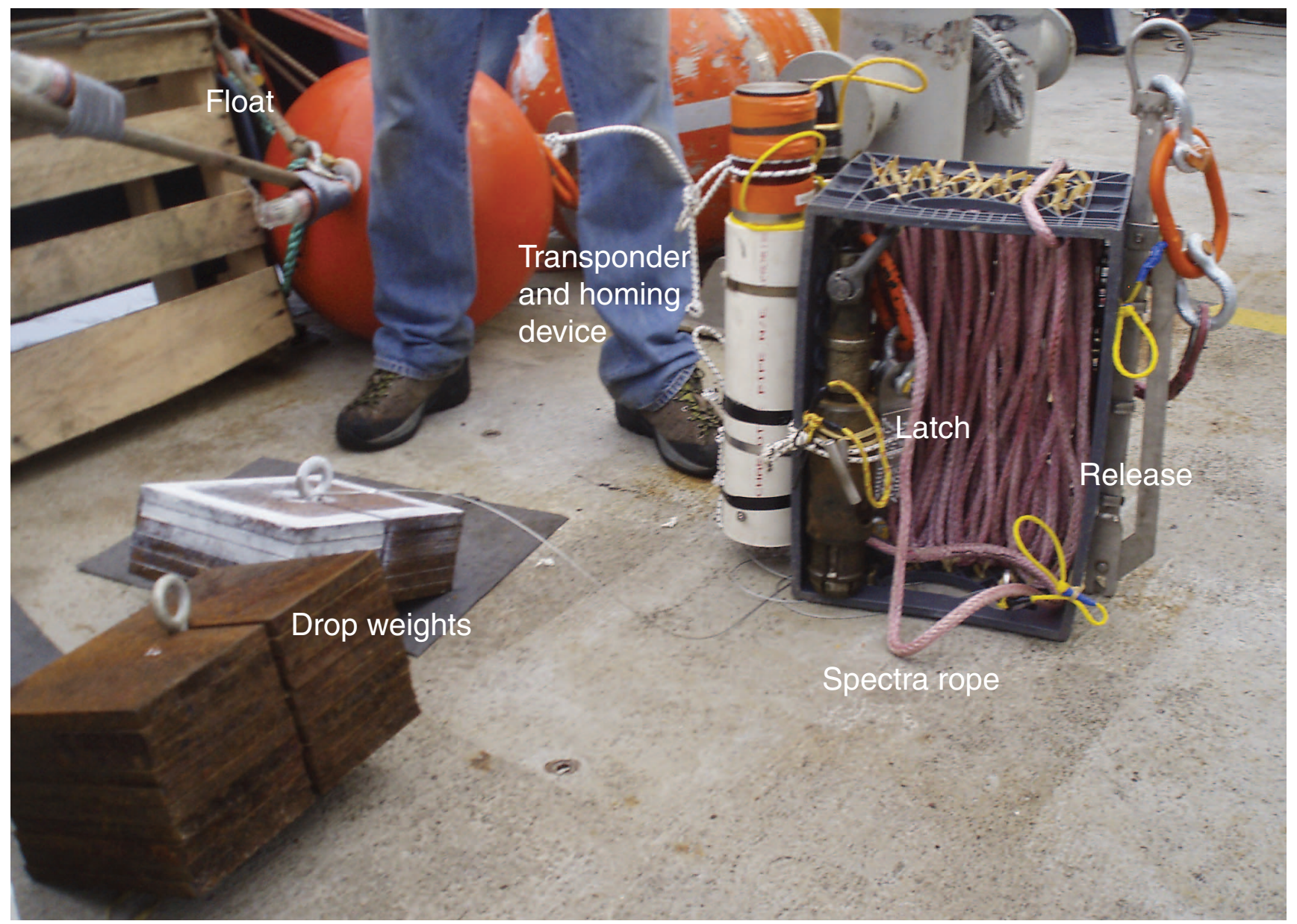


Table T1. Expeditions, locations, and hole numbers for CORK deployments. (See table note.)

\begin{tabular}{|c|c|c|c|c|}
\hline Leg/Expedition & Year & Location/Expedition name & Hole/Site & Reference \\
\hline 139 & 1991 & Middle Valley & $857 C, 858 \mathrm{G}$ & Davis, Mottle, Fisher, et al., 1992 \\
\hline 146 & 1992 & Cascadia margin & $889 C, 892 B$ & Westbrook, Carson, Musgrave, et al., 1994 \\
\hline 156 & 1994 & Northern Barbados Ridge & $948 \mathrm{D}, 949 \mathrm{C}$ & Shipley, Ogawa, Blum, et al., 1995 \\
\hline 168 & 1996 & Eastern flank of Juan de Fuca Ridge & $1024 \mathrm{C}, 1025 \mathrm{C}, 1026 \mathrm{~B}, 1027 \mathrm{C}$ & Davis, Fisher, Firth, et al., 1997 \\
\hline 174B & 1997 & North Pond & $395 \mathrm{~A}$ & Becker, Malone, et al., 1998 \\
\hline 195 & 2001 & South Chamorro Seamount & $1200 \mathrm{C}$ & Salisbury, Shinohara, Richter, et al., 2002 \\
\hline 196 & 2001 & Nankai Trough accretionary prism & $808 I, 1173 B$ & Mikada, Becker, Moore, Klaus, et al., 2002 \\
\hline 205 & 2002 & Costa Rica convergent margin & $1253 \mathrm{~A}, 1255 \mathrm{~A}$ & Morris, Villinger, Klaus, et al., 2003 \\
\hline 301 & 2004 & Eastern flank of Juan de Fuca Ridge & U1301A, U1301B, 1026B & Fisher, Urabe, Klaus, and the Expedition 301 Scientists, 2005 \\
\hline 319 & 2009 & NanTroSEIZE & C0010A & Saffer, McNeill, Byrne, Araki, Toczko, Eguchi, Takahashi, and the Expedition 319 Scientists, 2010 \\
\hline 327 & 2010 & Eastern flank of Juan de Fuca Ridge & U1362A, U1362B & This volume \\
\hline 328 & 2010 & Cascadia subduction zone ACORK observatory & $889 \mathrm{D}$ & Davis and Petronotis, 2010 \\
\hline 332 & 2010 & NanTroSEIZE & $\mathrm{C} 0002 \mathrm{G}, \mathrm{C} 0010 \mathrm{~A}$ & Kopf et al., 2010 \\
\hline 336 & 2011 & Mid-Atlantic Ridge flank microbiology, North Pond & $395 \mathrm{~A}$ and two new CORKs & Edwards et al., 2010 \\
\hline TBA & 2012 & Cascadia subduction zone & $889, \mathrm{U} 1327, \mathrm{U} 1328$ & None \\
\hline
\end{tabular}

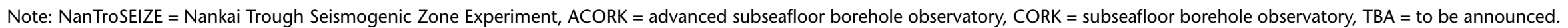

